\title{
Integrated "omics" profiling indicates that miRNAs are modulators of the ontogenetic venom composition shift in the Central American rattlesnake, Crotalus simus simus
}

Jordi Durban, Alicia Pérez , Libia Sanz , Aarón Gómez², Fabián Bonilla², Santos Rodríguez², Danilo Chacón², Mahmood Sasa ${ }^{2}$, Yamileth Angulo², José M Gutiérrez ${ }^{2}$ and Juan J Calvete ${ }^{1 *}$

\begin{abstract}
Background: Understanding the processes that drive the evolution of snake venom is a topic of great research interest in molecular and evolutionary toxinology. Recent studies suggest that ontogenetic changes in venom composition are genetically controlled rather than environmentally induced. However, the molecular mechanisms underlying these changes remain elusive. Here we have explored the basis and level of regulation of the ontogenetic shift in the venom composition of the Central American rattlesnake, Crotalus s. simus using a combined proteomics and transcriptomics approach.

Results: Proteomic analysis showed that the ontogenetic shift in the venom composition of C. s. simus is essentially characterized by a gradual reduction in the expression of serine proteinases and PLA $A_{2}$ molecules, particularly crotoxin, a $\beta$-neurotoxic heterodimeric PLA $A_{2}$ concominantly with an increment of PI and PIII metalloproteinases at age 9-18 months. Comparison of the transcriptional activity of the venom glands of neonate and adult C. s. simus specimens indicated that their transcriptomes exhibit indistinguisable toxin family profiles, suggesting that the elusive mechanism by which shared transcriptomes generate divergent venom phenotypes may operate post-transcriptionally. Specifically, miRNAs with frequency count of 1000 or greater exhibited an uneven distribution between the newborn and adult datasets. Of note, 590 copies of a miRNA targeting crotoxin B-subunit was exclusively found in the transcriptome of the adult snake, whereas 1185 copies of a miRNA complementary to a PIII-SVMP mRNA was uniquely present in the newborn dataset. These results support the view that age-dependent changes in the concentration of miRNA modulating the transition from a crotoxin-rich to a SVMP-rich venom from birth through adulhood can potentially explain what is observed in the proteomic analysis of the ontogenetic changes in the venom composition of C. s. simus.

(Continued on next page)
\end{abstract}

\footnotetext{
* Correspondence: jcalvete@ibv.csic.es

${ }^{1}$ Instituto de Biomedicina de Valencia, Consejo Superior de Investigaciones

Científicas, Jaime Roig 11, Valencia 46010, Spain

Full list of author information is available at the end of the article
} 
(Continued from previous page)

Conclusions: Existing snake venom toxins are the result of early recruitment events in the Toxicofera clade of reptiles by which ordinary genes were duplicated, and the new genes selectively expressed in the venom gland and amplified to multigene families with extensive neofunctionalization throughout the approximately 112-125 million years of ophidian evolution. Our findings support the view that understanding the phenotypic diversity of snake venoms requires a deep knowledge of the mechanisms regulating the transcriptional and translational activity of the venom gland. Our results suggest a functional role for miRNAs. The impact of specific miRNAs in the modulation of venom composition, and the integration of the mechanisms responsible for the generation of these miRNAs in the evolutionary landscape of the snake's venom gland, are further challenges for future research.

Keywords: Ontogenetic venom shift, Venomics, Snake venom gland transcriptomics, 454 pyrosequencing, Ion-Torrent microRNA profiling, Crotalus simus simus

\section{Background}

The presence of a venom system is a shared derived character of the advanced snakes [1-3]. Venom represents an adaptive trophic trait in snake evolution [4-7] that has played a central role in the origin of the advanced snakes during the Cenozoic era $[8,9]$. The diversity of modern snakes appeared during the Paleocene period of the Cenozoic Era, approximately 54-64 Mya, following the split of the Pareatidae from the remaining Caenophidians [6]. In Occidental culture, Francesco Redi (1626-1697), court physician to Ferdinando II de' Medici, Grand Duke of Tuscany and his successor, Cosimo III, is credited for discovering how vipers produce venom and inject it into their prey [10]. One century latter, Abbé Gasparo Ferdinando Felice Fontana (1730-1805), first director of the Museum of Physics and Natural History in Florence, performed experiments on the venom of the European viper. His classic text published in 1781 [11] is regarded the Opera Prima of modern toxinology [12].

Research on venoms has been continuously advanced by technological developments [13]. Particularly for the past decade, and fueled by the application of "omic" technologies [14-18], the field of molecular toxinology has experienced a sustained exponential growth. In-depth venom proteomics and transcriptomic analyses have recently become available for a number of venomous snake lineages, revealing a vast unexplored source of evolutionary innovation $[2,19,20]$. Snake venoms are well documented as having different venom compositions and toxicity based on taxonomic or geographical locations [21]. Inter- and intraspecific individual, gender-specific, regional, and seasonal variations in venom toxin composition may reflect local adaptations conferring fitness advantages to individuals specializing on different prey, or phylogenetic carry on. Understanding the processes that drive the evolution of snake venom variability is a topic of intense research interest in molecular and evolutionary toxinology. Recent studies of the molecular basis of adaptations have sought to understand the relative importance of gene regulation effects as determinants of venom phenotype [6,22-24]. Most significantly, a number of snakes show age-related (ontogenetic) changes in venom composition [25-32]. Surprisingly, despite previous suggestions that ontogenetic changes in venom are prey-related [33], juvenile Dusky Pigmy rattlesnakes, Sistrurus miliarius barbouri, raised on different diets showed similar albeit highly-variable venom compositions by the end of a 26-months study, suggesting little effect of diet on the overall make-up of venom in snakes this age or younger [23]. Over the same period shifts in venom composition occurred in females raised on different prey in all diet treatments with the magnitude of those changes strongly related to diet. This work provided evidence that venom composition is somewhat plastic in both juvenile and adult $S . m$. barbouri and that, at least in adults, prey consumed may influence the relative abundance of possibly functionally-distinct classes of venom proteins [23]. However, the molecular mechanisms that underly age-related changes in venom remain elusive.

In this work we have explored the basis and level of regulation of the ontogenetic shift in the venom composition of the Central American rattlesnake, Crotalus s. simus. Biogeographical data indicate a basal cladogenesis in the Central American C. simus clade, dating back to the late Miocene/early Pliocene (6.4-6.7 Mya) [34]. Neonate and juvenile $C$. s. simus venoms contain large relative amounts of crotoxin, a heterodimeric $\mathrm{PLA}_{2}$ molecule exhibiting presynaptic $\beta$-neurotoxicity, along with low concentration of hemorrhagic snake venom metalloproteinases (SVMPs) [29]. By contrast, adult C. $s$. simus venom presents a high content of SVMP and is largely devoid of neurotoxic activity [29,35,36]. Juvenile and adult C. s. simus venom phenotypes broadly correspond, respectively, to type II (low metalloproteinase activity and high toxicity, $\mathrm{LD}_{50}<1 \mu \mathrm{g} / \mathrm{g}$ mouse body weight) and type I (high levels of SVMPs and low toxicity, $\mathrm{LD}_{50}>1 \mu \mathrm{g} / \mathrm{g}$ mouse body weight) venoms defined by Mackessy [37,38]. Here we investigate the transition from type II to type I venom phenotype in C. s. simus through an integrated "omics" approach involving proteomic survey of 
time-course venom composition variation, from birth through adulthood, and Next Generation sequencing of the venom gland transcriptomes and microRNAs of neonate and adult specimens. With this experimental design we intended to determine whether venom gene expression is transcriptionally controlled by developmental stage-dependent factors, or whether the ontogenetic changes in venom composition involve regulation at the post-transcriptional level.

\section{Results and discussion}

Time-resolved proteomic analysis of the ontogenetic changes in the venom composition of C. s. simus

A previous proteomic survey of the venom of the Central American rattlesnake, $C$. s. simus, laid the foundation for understanding the changes in toxin composition and overall pharmacological features between adult (predominantly hemorrhagic) and newborn (mainly neurotoxic) snakes [29]. This study revealed prominent stage-dependent protein expression changes between the pooled venoms from newborn and adult specimens from Costa Rica, characterized by a shift from a type II to a type I venom phenotype [29]. Such a conspicuous venom composition change has been hypothesized to be related to variations in the size of prey consumed by snakes of different ages and the variable requirements for immobilizing and digesting them $[37,38]$. It has also been suggested that the significance of venom adaptation to specific diets represents a trade-off between the metabolic cost of venom production and increasing foraging efficiency $[7,39]$. In the present work we have sought to establish the molecular mechanism responsible for the reported ontogenetic shift in venom protein composition.

Figure 1 presents reverse-phase HPLC profiles showing changes in the composition of venom pooled from specimens from age 8-weeks to adulthood ( $\geq 36$ months). The ontogenetic shift is essentially characterized by a gradual reduction in the expression of serine proteinases and $\mathrm{PLA}_{2}$ molecules, particularly crotoxin, a $\beta$-neurotoxic heterodimeric $\mathrm{PLA}_{2}$ [40-42], concomitantly with an increased secretion of PI and PIII SVMPs at age 9-18 months. Of particular note, whereas venoms from individual 9-month-old C. S. simus specimens showed indistinguishable reverse-phase chromatographic profiles, venoms from 18-month-old snakes exhibited large individual variation in their crotoxin and SVMP contents (Figure 2), suggesting a key point in shifts in venom composition at this developmental stage. Consistent with this view, juvenile specimens around this age exhibit a range of venom phenotypes, between predominantly type I, type II, and combinations of the two. Systemic effects involving hemostatic disturbances, i.e. coagulopathy, have not been documented in Central American rattlesnake envenomings [35,43]. However, there is little information on the clinical observations of envenomings induced by specimens of $C$. simus of various ages in Central America. Envenomings by adults are characterized by local tissue damage, i.e. edema and hemorrhage and systemic manifestations associated with cardiovascular effects and coagulopathy [43]. Our proteomic data suggest that bites by juvenile specimens might be characterized by a combination of SVMP-induced hemorrhage and crotoxininduced neurotoxicy, in addition to serine proteinaseinduce coagulopathy. Thus variable clinical manifestations might occur in accidents by $C$. simus of different ages. A similar trend regarding geographical differences in venom composition and toxicity has been described in the literature for the North American Mojave rattlesnake, C. s. scutulatus. Venom populations of C. s. scutulatus exhibit an intergradation pattern from SVMP-rich (type B) to Mojave toxin-rich (type A) phenotypes, from south central to southeastern Arizona [44]. Type A venom has large amounts of Mojave (crotoxin-like) toxin and shows neurotoxic effects. Type B venom has large amounts of SVMPs and shows hemorrhagic effects, and type $A+B$ venom is a combination of the two and induces both neurotoxic and hemorrhagic effects [45,46]. Geographic venom variation throughout the C. s. scutulatus range correlated with clinical severity outcomes [44]. Hence, besides ecological and taxonomical implications, knowledge of the natural history and toxin composition of venoms is of fundamental importance for the treatment of bite victims and for the selection of specimens for the preparation of venom pools for antivenom production $[47,48]$.

\section{Analysis of the venom gland transcriptomes of neonate and adult $C$. s. simus. Retroelements}

To investigate the basis of the ontogenetic venom shift revealed by the time-resolved proteomic analysis, we compared the transcriptional activity of the venom glands of a neonate and an adult C. s. simus specimens, using 454 pyrosequencing and the bioinformatic processing strategy outlined in Durban et al. [15]. 408,505 and 349,170 raw 454 reads from adult and newborn venom gland transcriptomes, respectively, were quality trimmed using the Prinseq software and only reads having a Quality Value (QV) greater than 20 [49] (355,140 (adult) and 320,907 (newborn) Table 1) were considered for assembling with Newbler 2.6 software. The analysis yielded 33,408 (adult) and 24,136 (newborn) singletons, and among the resulting 6,484 (adult) and 6,047 (newborn) total contigs, $1.43 \%$ and $10.74 \%$ comprised only 2 reads. Table 1 displays a summary of the 454 sequencing statistics.

Contig sequences were inspected for repetitive elements using Repeat Masker. 97,204 bases (1.93\% of adult C. $s$. simus venom gland transcriptome) and 65,742 nucleotides (1.94\% of the newborn venom gland transcriptome) were masked with $\mathrm{N}$ characters, a large part of them 

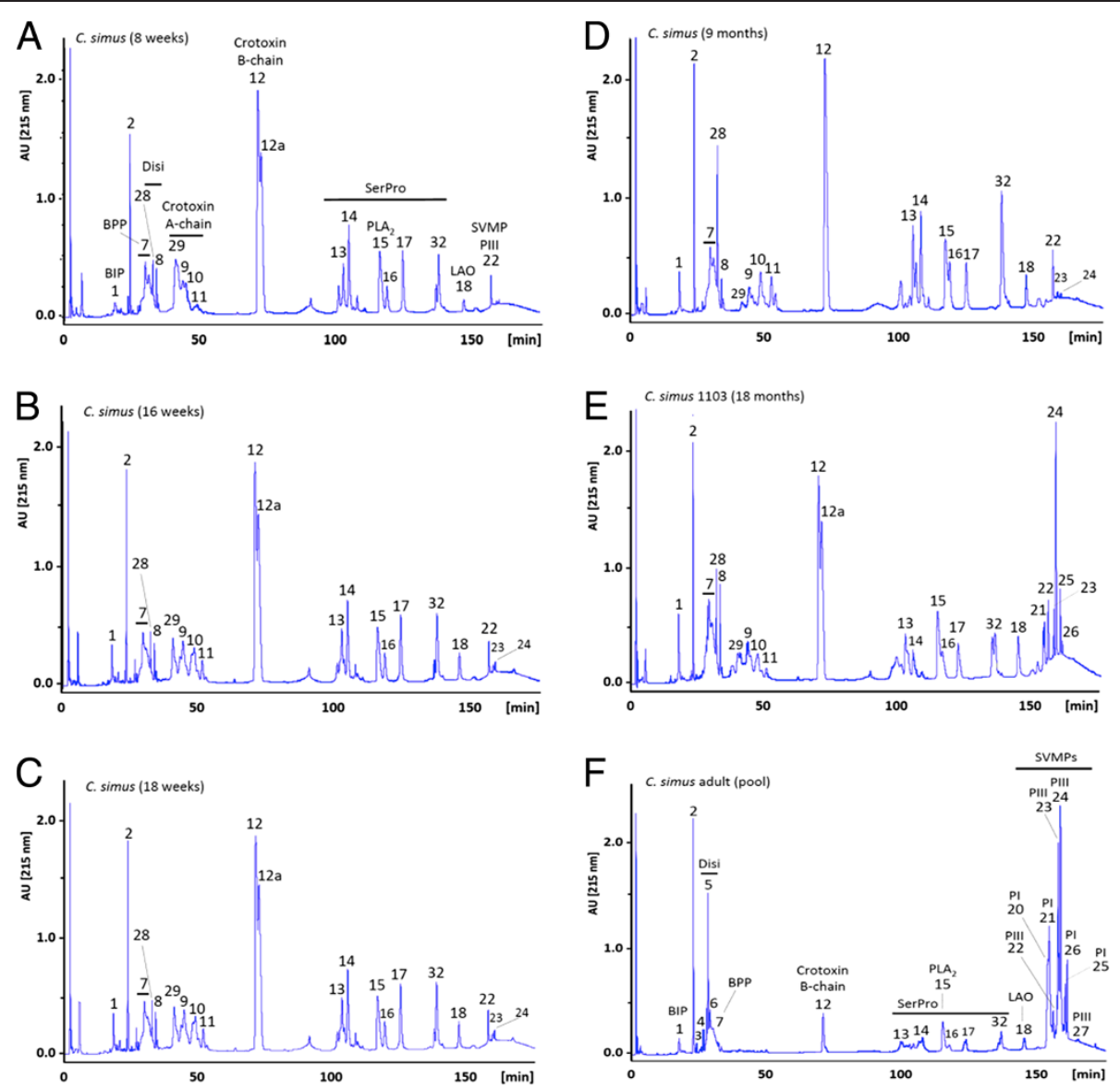

Figure 1 Proteomic analysis of the ontogenetic changes in the venom composition of $\mathbf{C}$. simus. Panels A-F display reverse-phase HPLC profiles changes of pooled venoms collected from specimens from age 8 -weeks to adulthood ( $\geq 36$ months). Chromatographic fraction numbers and their identities correspond to those previously identified by Calvete et al. [Figure 1 and Table of ref. 29]. BIP, bradykinin-inhibitory peptide; BPP, bradykinin-potentiating peptides; Disi, disintegrin; SerProt, serine proteinase; PLA 2 , phospholipase $A_{2} ;$ LAO, L-amino acid oxidase; PI and PIII, snake venom metalloproteases (SVMP) of class PI and PIII, respectively; Peaks 29, 9, 10, and 11, crotoxin A-chain [UniProtKB accession code P08878]; peak 12, crotoxin B-chain-1 [P62022]; peak 12a, crotoxin B-chain-2 [P24027].

comprising Short and Long INterspersed repetitive Elements (SINEs and LINEs) retroelements (Additional file 1: Tables S1 and S2). Transposable elements (TE) that propagate within the host genome via RNA intermediates occupy a large fraction of eukaryotic genomes. Their mobility and amplification represent a major source of genomic variation [50,51]. Retrotransposable elements have been reported in the transcriptomes of Bothrops insularis (4.1\% of ESTs) [52], Lachesis muta (0.3\%) [53], and Philodryas olfersii (4.1\%) [54], in $\mathrm{PLA}_{2}$ genes from the venom gland of Vipera ammodytes [55,56] and Protobothrops flavoviridis [57,58], and in an E. ocellatus PIII-SVMP gene [59]. Although their functional relevance in the venom gland remains unknown, transposable elements appear to be overrepresented in UTRs of mRNAs of rapidly evolving genes [60], suggesting that they have played a role in the diversification and expansion of these gene families $[61,62]$.
Sauria SINE have been characterized in all major lineages of squamate reptiles [62,63], and phylogenetic analysis of E. ocellatus Sauria SINEs [57] indicated that their origin correlates with the time frame of the evolution of the snake venom system. Sauria SINEs may have arisen by a fusion of a tRNA-related sequence with the 3' end of a LINE [64] more than 200 million years ago and are uniquely widespread in lepidosaurian genomes [62]. SINEs have no protein coding capacity, and their retrotransposition depends on a "targetprimed reverse transcription" by autonomous partner LINEs, that encode an endonuclease for cleaving the genomic integration site and a reverse transcriptase to copy the RNA to DNA [65,66]. Since Sauria SINEs share an identical 3 ' sequence with Bov-B LINEs, it has been proposed [63] that they utilize in trans the enzymatic machinery of Bov-B LINEs for their mobility and dispersal throughout the genome. In squamates 

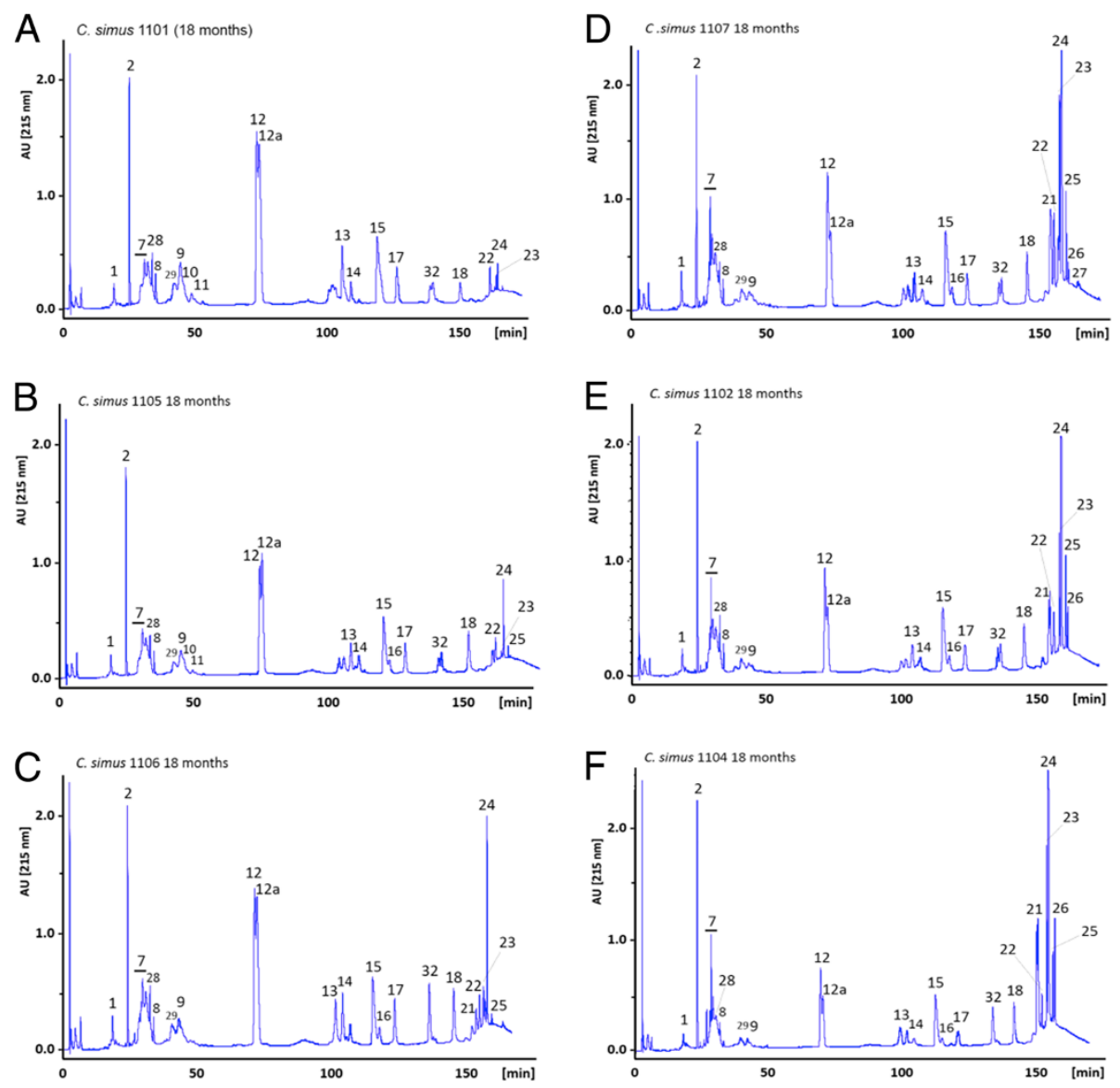

Figure $\mathbf{2}$ Individual variability in the venom composition of $\mathbf{1 8 - m o n t h}$ old $\mathbf{C}$. simus. Panels A-F display reverse-phase HPLC separations of the venom of six C. simus siblings illustrating the range of venom phenotypes observed at age 18 months. Peak numbering as in Figure 1.

and turtles, CR1 and L2 LINES are also partners of diverse SINEs [63,67].

An overview of the landscape of retrotransposable elements reported in the sauropsida taxon, a sister group of mammals that includes all extant reptiles and birds, has recently emerged from analysis of the draft genomes of the red jungle fowl, Gallus gallus [68], and the green anole, Anolis carolinensis [69]. Whereas a single type of LINE, CR1, comprises over $80 \%$ of all interspersed repeats in the chicken genome (200,000 copies; $9 \%$ of the chicken genome), approximately $30 \%$ of the $A$. carolinensis genome is composed of a wide diversity of LINE and SINE mobile element families. Since SINEs are among the largest multigene families in reptilian genomes, they may act as sites for homologous recombination events between dispersed SINEs, resulting in a variety of genetic rearrangements, including duplication, deletion and translocation, that likely represent mechanisms that generates genetic diversity in reptilian genomes [70]. The prevalence of transposable elements in untranslated regions of mRNAs of recently expanded gene classes suggested that TEs could affect gene expression through the donation of transcriptional regulatory signals [60]. The indistinguishable distribution of TEs in the venom gland transcriptomes of neonate and adult C. s. simus (Additional file 1: Tables S1 and S2) argues against this type of transcriptional regulation to explain the ontogenetic shift in venom composition.

Table 1454 sequencing statistics

\begin{tabular}{lllllllll}
\hline & Total reads & $\begin{array}{l}\text { Mean length } \\
\text { read (nt) }\end{array}$ & $\begin{array}{l}\text { Max. length } \\
\text { read (nt) }\end{array}$ & $\begin{array}{l}\text { Assembled } \\
\text { reads (\%) }\end{array}$ & $\begin{array}{l}\text { Number of } \\
\text { contigs }\end{array}$ & $\begin{array}{l}\text { Mean length } \\
\text { contig (nt) }\end{array}$ & $\begin{array}{l}\text { Max. length } \\
\text { contig (nt) }\end{array}$ & $\begin{array}{c}\text { Singletons } \\
\text { Newborn }\end{array}$ \\
\hline 320,907 & 567.5 & 1,193 & $276,729(86.23)$ & 6,047 & 560.87 & 5,857 & 24,136 \\
Adult & 355,140 & 535.4 & 1,320 & $296,470(83.48)$ & 6,484 & 777.88 & 5,947 & 33,408 \\
\hline
\end{tabular}

Raw reads, Roche Signal Processing Application reads, and Newbler 2.6-assembled contigs were inspected for poly- $\mathrm{N}$ 's, the presence of library construction tags, and their Quality Values (QV). Only reads showing a QV > 20 were assembled. 
Comparison of toxin-coding transcript distribution in newborn and adult C. s. simus transcriptomes provides clues for streamlining their divergent venom phenotypes The sets of 6,484 (adult) and 6,047 (newborn) masked contigs were searched against the NCBI nucleotide sequence database using the BLASTN algorithm to identify similar sequences. 4,141 hits representing $63.9 \%$ of the total contigs of the adult snake transcriptome were retrieved, 431 of which $(10.4 \%$ of matched hits) displayed similarity (e-value cutoff $<10^{-3}$ ) to documented venom proteins of the taxonomic suborder Serpentes. In addition, 21,460 singleton sequences $(64.23 \%$ of the total adult venom gland singletons, Table 1) produced significant BLASTN hits, and of these only 431 (2\%) corresponded to documented snake venom entries.

On the other hand, 3,022 (49.9\% of the newborn venom gland transcriptome) found a BLAST hit, including 658 (10.9\%) matches to snake venom proteins. Also, 526 sequences out of the 15,052 singleton BLAST hits (3.5\%) corresponded to snake venom toxins. Additional file 2: Table S3 lists the relative abundances of the different venom protein family hits in the non-normalized venom gland transcriptomes of newborn and adult C. s. simus. The venom protein families identified in the newborn and adult venom gland transcriptomes, and the relative abundances of the length-normalized ORFs, simulated with NoiSeq for five technical replicates (nss=5), are displayed, are listed in Table 2. An estimation of the minimum number of genes from each toxin family transcribed into the venom gland transcriptome was calculated from the multiple alignments of reads matched to a full-length reference sequence [15] (Table 3). These newborn and adult synthetic gene sequences were clustered with CD-HIT into shared (identity threshold $>0.8$ ) and unique clusters (Table 3). Figure 3 shows the distribution of clusters from the major toxin families between newborn and adult transcriptomes. These results indicated that both newborn and adult C. S. simus venom glands expressed non-overlapping gene sets. In particular, C-type lectin-like (CTL), (nerve growth factor) NGF, phospholipase $\mathrm{A}_{2}\left(\mathrm{PLA}_{2}\right)$, and snake venom metalloproteinase (SVMP) toxin families exhibited high NOISeq probabilities (prob value $=0.98,0.93,0.96$, and 0.91 , respectively) of being differentially expressed between the adult and the newborn transcriptomes. CTL, NGF, and SVMP toxin families were down-regulated in newborn versus adult database $(-2.01,-1.69$, and $0-77$, respectively), whereas the $\mathrm{PLA}_{2}$ family appeared to be up-regulated (1.49).

Figure 4 displays chart pies comparing the relative protein family compositions computed from the adult and newborn transcriptomes (Table 2) and the venom proteomes [15]. The amino acid sequences of transcriptdeduced amino acid sequences of $\mathrm{PLA}_{2}$ molecules, serine proteinases, and SVMPs are shown in Additional file 3: Figures S1-S3). In line with previous transcriptomic

Table 2 RPKM (Reads per Kilobase per Million mapped reads)-normalized contigs and singletons from the venom gland transcriptomes of newborn and adult C. s. simus aligned to a reference snake venom toxin ORF

\begin{tabular}{|c|c|c|c|c|c|c|c|c|c|c|}
\hline & \multicolumn{5}{|c|}{ Newborn } & \multicolumn{5}{|c|}{ Adult } \\
\hline & Contigs & Reads & Singletons & RPKM & $\%$ & Contigs & Reads & Singletons & RPKM & $\%$ \\
\hline 5'-NTase & 1 & 395 & 1 & 212.20 & 0.06 & 2 & 334 & 0 & 532.54 & 0.08 \\
\hline$\underline{\mathrm{BPP}}$ & 2 & 42 & 1 & 74.66 & 0.02 & 1 & 11 & 0 & 56.83 & 0.01 \\
\hline CRISP & 3 & 62 & 0 & 81.26 & 0.02 & 0 & 0 & 0 & 0 & 0 \\
\hline $\mathrm{CTL}$ & 6 & 483 & 5 & $1,035.42$ & 0.31 & 13 & 1,462 & 4 & $9,255.5$ & 1.5 \\
\hline GC & 1 & 143 & 2 & 124.08 & 0.04 & 3 & 348 & 2 & 891.07 & 0.14 \\
\hline HYA & 2 & 346 & 4 & 245.52 & 0.07 & 4 & 369 & 1 & 772.30 & 0.12 \\
\hline KUN & 2 & 15 & 0 & 18.70 & 0.01 & 2 & 115 & 3 & 437.76 & 0.07 \\
\hline$\underline{\mathrm{LAO}}$ & 1 & 1,300 & 0 & 793.68 & 0.24 & 1 & 1,440 & 1 & $2,617.77$ & 0.42 \\
\hline NGF & 1 & 384 & 0 & 501.22 & 0.15 & 1 & 917 & 4 & $3,577.02$ & 0.58 \\
\hline $\mathrm{OHA}$ & 0 & 0 & 0 & 0 & 0 & 0 & 0 & 0 & 0 & 0 \\
\hline PDE & 1 & 308 & 0 & 383.50 & 0.11 & 1 & 77 & 0 & 285.28 & 0.04 \\
\hline$\underline{\mathrm{PLA}}$ & 27 & 41,700 & 37 & $94,942.21$ & 28.37 & 18 & 11,015 & 9 & $74,618.46$ & 12.13 \\
\hline$\underline{\text { SVMP }}$ & 48 & 54,601 & 79 & $28,306.34$ & 8.46 & 62 & 69,198 & 62 & $106,685.8$ & 17.34 \\
\hline$\underline{\mathrm{SP}}$ & 191 & 156,291 & 194 & $207,689.54$ & 62.07 & 83 & 105,104 & 62 & $415,323.2$ & 67.51 \\
\hline VEGF & 2 & 132 & 2 & 219.77 & 0.07 & 4 & 19 & 0 & 92.72 & 0.01 \\
\hline
\end{tabular}

Abbreviations: 5'-NTase 5'-nucleotidase, BPP bradykinin potentiating peptide, CRISP cysteine-rich secretory protein, CTL C-type lectin-like protein, GC glutaminyl cyclase, HYA hyaluronidase, KUN Kunitz-type inhibitor, LAO L-amino acid oxidase, NGF nerve growth factor, OHA ohanin, $P D E$ phosphodiesterase, $P L A_{2}$ phospholipase $A_{2}$, SVMP snake venom metalloproteinase, SP serine proteinase, VEGF vascular endothelial growth factor. Protein families found in $C$. s. simus proteome [15] are underlined. 


\begin{tabular}{|c|c|c|c|}
\hline Toxin family & $\begin{array}{l}\text { Newborn } \\
\text { Unique }\end{array}$ & Adult & $\begin{array}{l}\mathrm{N}+\mathrm{A} \\
\text { Shared }\end{array}$ \\
\hline 5'-NTase & & & 1 \\
\hline $\mathrm{BPP}$ & 2 & 1 & \\
\hline CRISP & 3 & & \\
\hline$C T L$ & 6 & 2 & \\
\hline GC & & & 1 \\
\hline HYA & 1 & & 1 \\
\hline KUN & 2 & 2 & \\
\hline$\underline{\mathrm{LAO}}$ & & & 1 \\
\hline NGF & & & 1 \\
\hline PDE & & & 1 \\
\hline$\underline{\mathrm{PLA}}$ & 2 & 1 & 5 \\
\hline SVMP & 7 & 7 & 7 \\
\hline$\underline{S P}$ & 15 & 0 & 50 \\
\hline VEGF & 2 & 1 & \\
\hline
\end{tabular}

Toxin family acronyms as in Table 2.

Protein families found in the respective venom proteomes [15] are underlined.

surveys, the overall composition of neonate and adult transcriptomes (Figure 4, pie charts "a" and "b") are more similar to each other than their respective proteomes (Figure 4, pie charts "c"), indicating that the venom transcriptome may be subjected to stage-dependent translational control. In particular, newborn and adult venom glands expressed similar amounts of a transcript encoding a protein sequence $100 \%$ identical to crotoxin Bchain [P62022], whereas the concentration of this protein markedly differ in their respective venom proteomes (compare peak 12,12b in between panels of Figure 1). Moreover, shared clusters 1, 2, and 4 encode precursor crotoxin A-chain [P08878]-like sequences, although this protein (peaks 29, 9-11 in Figure 1), which is necessary for generating the heterodimeric presynaptic $\beta$ neurotoxic $\mathrm{PLA}_{2}$ molecule [40,41] responsible for the neurotoxicity of newborn and juvenile Central and adult South American rattlesnakes [42,43], is absent from the venom of adult C. s. simus venom [29]. Similarly, cluster 5 , shared by newborn and adult venom gland transcriptomes (Figure 3B), encodes the PI-SVMP 20-21 exclusively found in venoms of juvenile (18-month) and adult specimens (Figure 1). Newborn and adult transcriptomes also share a number of clusters encoding PIII-SVMPs $(0,1,2,4,6$, and 16) although only a PIIISVMP (peak 22, Figure 1) is present in the venom proteome of snakes aged 0-9 month. Moreover, PIII-SVMPs $8,11,14$ and 18 and 9, 12, 15, 17 and 19 exhibited exclusive transcription in the newborn and the adult, respectively. On the other hand, although fragmentary, the protein sequences encoded by clusters 2, 12 and 15 match the MS/MS-derived peptide sequence information derived from the PIII-SVMPs 23-24 isolated from venom of adult snakes [29]. The higher diversity of serine proteinase transcripts characterized in the newborn versus the adult venom gland also mirrors the proteomic data (Figure 1). Shared cluster 0 (Figure 3C) encodes serine proteinase (SP) 14, an abundant enzyme in newborn and juvenile venom proteomes whose expression is significantly down-regulated in adult snakes (Figure 1). A precise matching of other venom serine proteinases characterized in C. s. simus is impeded by the lack of MS/MS data discriminating between the different transcript sequences (Additional file 3: Figure S3). Nevertheless, our results indicate that the age-dependent expression of both SP 14 and the major PIII-SVMPs found in adult C. s. simus venom might be due to a transcriptional regulatory mechanism. In addition, although it cannot be excluded that some shared transcripts correspond to pseudogenes, and also taking into consideration that the sampled transcriptomes were from single specimens, another main conclusion from our findings is that the molecular mechanism by which shared transcriptomes generate divergent venom phenotypes may operate post-transcriptionally.

\section{Distinct venom gland miRNA sets in newborn and adult snakes: modulators of the Central American rattlesnake's ontogenetic venom composition variation?}

Phenotypic diversity generated through the regulation of RNA transcripts has been proposed as an explanation for the discrepancy between organismal complexity and the relatively limited number of primary coding transcripts [72,73]. Regulation by micro RNAs is one such mechanism [74,75]. MicroRNAs (miRNAs) are a class of small ( 22 nucleotides in length), single-stranded, noncoding endogenous RNAs that are recently found to be negative post-transcriptional regulators of gene expression in eukaryotic organisms [76]. MicroRNAs act as adaptors that employ a silencing ribonucleoprotein complex to target mRNAs by selective Watson-Crick basepairing, primarily in the 3 '-UTR region. miRNAs anchored into specific binding pockets guide members of the Argonaute (Ago) protein family to target mRNA molecules for silencing or destruction [77]. The evolutionary dynamics of miRNAs across metazoan phylogeny and through deep evolutionary time suggests that metazoan morphological complexity might have its roots in miRNA innovation [78]. To explore the possible involvement of miRNAs in the post-transcriptional regulation of C. s. simus venom gland transcriptome, miRNA libraries from neonate and adult specimens were sequenced on an Ion Torrent Personal Genome Machine. Table 4A displays a summary of candidate miRNA 


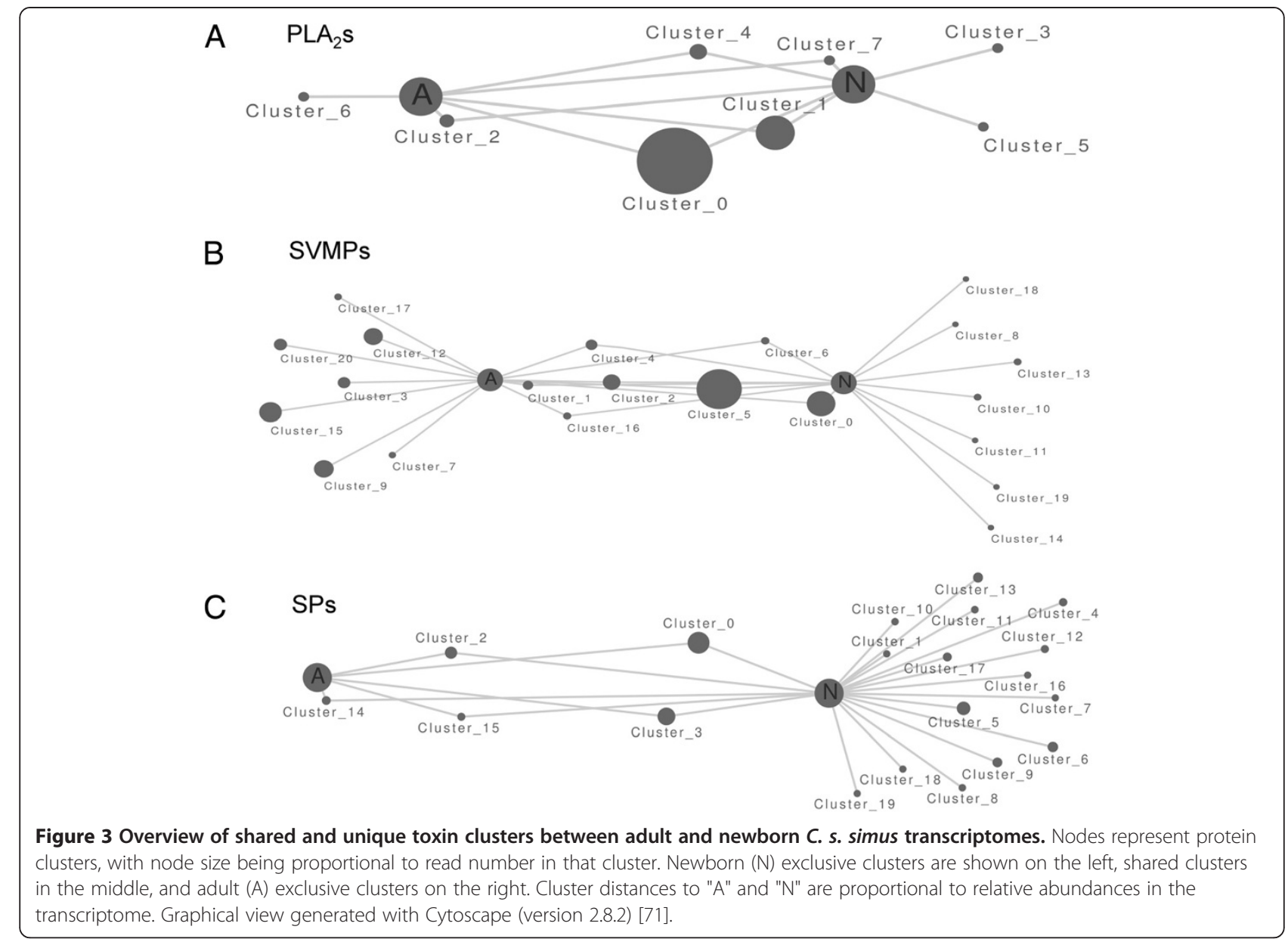

sequencing statistics. Candidate miRNAs were filtered out according to nucleotide length and the presence of either the 30-mer IonA or the 23-mer P1 adapter sequences. This quality processing step yielded 38,738 (newborn) and 64,493 (adult) clusters, of which, respectively, 238 and 419 comprised at least 100 reads
(Table 4B). These newborn and adult datasets contained 132 and 268 unique miRNAs, respectively, and 151 were shared between them (Table 4B). Although to date no snake miRNA has been reported in miRBase (http://www. mirbase.org), which includes 21,643 mature miRNA products from 168 species [79], BLAST analysis of C. s. simus

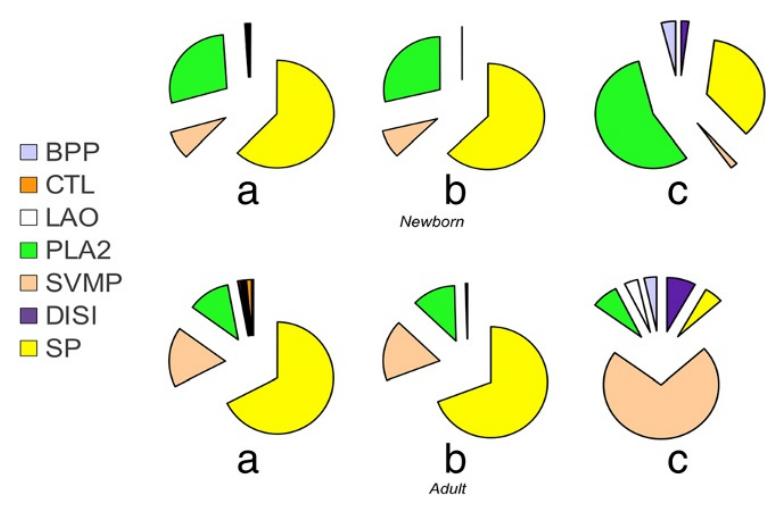

Figure 4 Comparison of the protein composition of adult and newborn C. s. simus transcriptomes. Chart pies "a" display the relative occurrence of RPKM-normalized ORF-coding reads listed in Table 2 in the venom gland transcriptomes of adult and newborn C. s. simus. Chart pies "b" display the same distribution as "a" but taking into account only protein families identified in the venom proteome [29]. Chart pies "c" show the toxin family composition of the venom proteomes of adult and newborn C. s. simus (data taken from [29]). 
Table 4 A. Summary of candidate miRNA sequencing statistics. B. Clustering and miRBase annotation statistics

\begin{tabular}{llllllll}
\hline A & Total raw reads & $\begin{array}{l}\text { Prinseq quality } \\
\text { filtered reads }\end{array}$ & $\begin{array}{l}\text { FastX too-short } \\
\text { reads }\end{array}$ & $\begin{array}{l}\text { FastX adapter-only } \\
\text { reads }\end{array}$ & $\begin{array}{l}\text { Processed } \\
\text { reads }\end{array}$ & $\begin{array}{l}\text { Mean length } \\
\text { read (nt) }\end{array}$ \\
\hline Newborn & 314,592 & 263,517 & 34,579 & 8,390 & 220,548 & 24.58 \\
Adult & 515,040 & 450,902 & 55,882 & 5,956 & 389,064 & 23.68 \\
\hline B & Total clusters & $\geq 100$ reads & Unique clusters & Shared clusters & BLAST miRBase hits & Anolis hits & $\%$ Anolis hits \\
\hline Newborn & 38,738 & 283 & 132 & 151 & 48 & 22 & 45.8 \\
Adult & 64,493 & 419 & 268 & 151 & 70 & 30 & 42.8 \\
\hline
\end{tabular}

Total clusters were obtained after the CD-HIT usage. Clusters were compared between newborn and adult datasets and blasted against miRBase.

the adult and newborn miRNA datasets against the mature miRBase retrieved 118 hits matching such diverse taxa as mammals (gray short-tailed opossum, Monodelphis domestica; platypus, Ornithorhynchus anatinus; Tasmanian devil, Sarcophilus harrisii; bull, Bos taurus; horse, Equus caballus; Sumatran orangutan, Pongo abelii; wild boar, Sus scrofa; mouse, Mus musculus,), birds (zebra finch, Taeniopygia guttata), fishes (sea lamprey, Petromyzon marinus; Japanese ricefish, Oryzias latipes; zebra fish, Danio rerio), reptile (Anole lizard, Anolis carolinensis), and the solitary sea squirt, Ciona intestinalis (Ascidian). However, 52 miRNA sequences (44\%) corresponded to miRNAs reported in Anolis carolinensis, the only available squamate genome [69].

MicroRNAs with frequency count of 1000 or greater exhibited a distinct distribution between the newborn and adult datasets (Figure 5). Noteworthy, the most expressed miRNAs in the newborn venom gland showed a significantly lower abundance in adults and visa versa, miRNAs abundantly expressed in adults have a lower expression in neonates (Figure 5, right panels; Tables S4 and S5 in Additional file 2). This uneven distribution of miRNAs suggests a regulatory mechanism by which a single transcriptome may result in different proteomes. Prediction of putative target genes was assessed by miRanda using the parameter specified in the Methods section. MiRanda is a bioinformatic tool for finding genomic targets for microRNAs that incorporates current biological knowledge on target rules and computes optimal sequence complementarity between a set of mature microRNAs and a given mRNA using a weighted dynamic algorithm [80-82]. MiRanda predicted 10 miRNAs complementary of 3'-UTR loci of C. s. simus SVMP 454transcripts (5 shared between newborn and adult; 5 newborn-exclusive) and 3 miRNAs from adult snakes targeting PLA $\mathrm{P}_{2}$ mRNAs (Figure 6; but see also Figure S4 in Additional file 3). When these matches were filtered through MapMi using thermodynamics, sequence conservation, and pairwise alignment criteria [83], positive hits were restricted to the three miRNA sequences mapping to PLA 2 loci (clusters New299/Ad368, New1849/Ad1078, and Ad2166) and a pair of miRNAs against SVMP mRNAs (clusters New4393/Ad3416 and New2578) (Figure 6).
miRNA counts in the newborn and adult venom gland transcriptomes, and best BLAST hits of their putative target genes are displayed in Figure 7. In addition, Table S6 (Additional file 2) lists the miRanda-only predicted miRNAs and their best BLAST hit, and Figure S4 (Additional file 3 shows their Watson-Crick pairing to target 3'-UTR loci of PLA2 and SVMP 454 transcripts, and the corresponding binding energy calculated by MapMi. Noteworthy, 590 copies of miRNA 2166, targeting crotoxin B-subunit, was exclusively found in the transcriptome of the adult snake whereas 1185 copies of miRNA 2578, complementary to a PIII-SVMP mRNA, was uniquely present in the newborn dataset (Figure 6).

Animal miRNAs guide proteins to repress the translation of target mRNAs via imperfect base pairing between the miRNA and the target [75]. Although the precise rules for pairing between a miRNA and its mRNA target sites are not known, an obvious requirement for miRNA regulation is the concurrent expression of both a miRNA and its target genes, and requiring conserved Watson-Crick pairing to the $5^{\prime}$ region of the miRNA centered on nucleotides 2-7 (the so-called miRNA "seed") markedly reduces the occurrence of false-positive predictions $[84,85]$. However, a modest role for 3'-supplementary in targeting specificity, and the rare occurrence of 3'-compensatory sites that can compensate for a single-nucleotide bulge or mismatch in the seed region, both centered on miRNA nucleotides 13-16/17, have been reported [86]. In addition, mismatch at position 1 is supported by biochemical and crystallographic studies, indicating that the 5'-most nucleotide of an Argonautebound guide RNA is not paired to the target strand [87,88]. Figure 8 and S6 (Additional file 2) display the complementarity between the dataset-exclusive miRNAs and their (miRanda + MapMi)-predicted $\mathrm{PLA}_{2}$ and SVMP target mRNA loci listed in Figure 7.

\section{Concluding remarks and perspectives}

The most important concept that emerges from our results is the possibility that miRNAs play a role in both the ontogenetic shift observed in certain venoms and in the plasticity of venoms from adult snakes underlying adaptations to changing environments. An important 

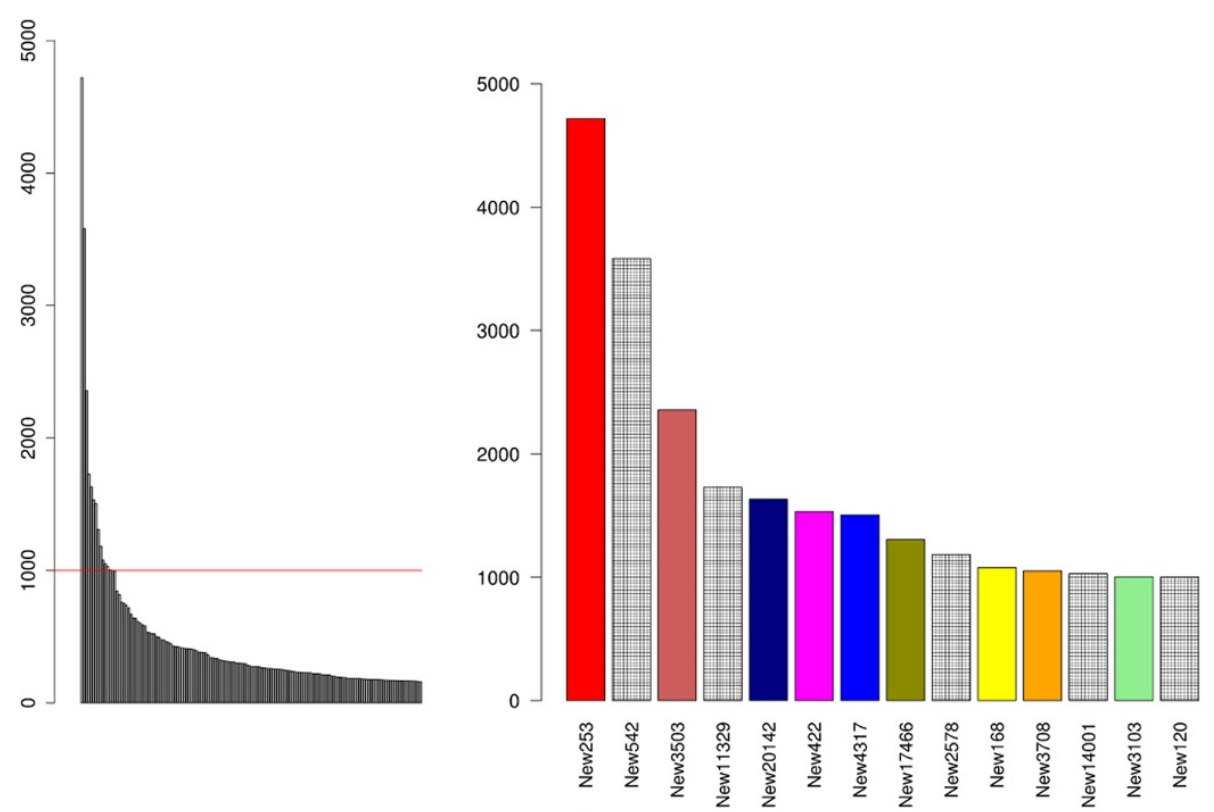

Newborn
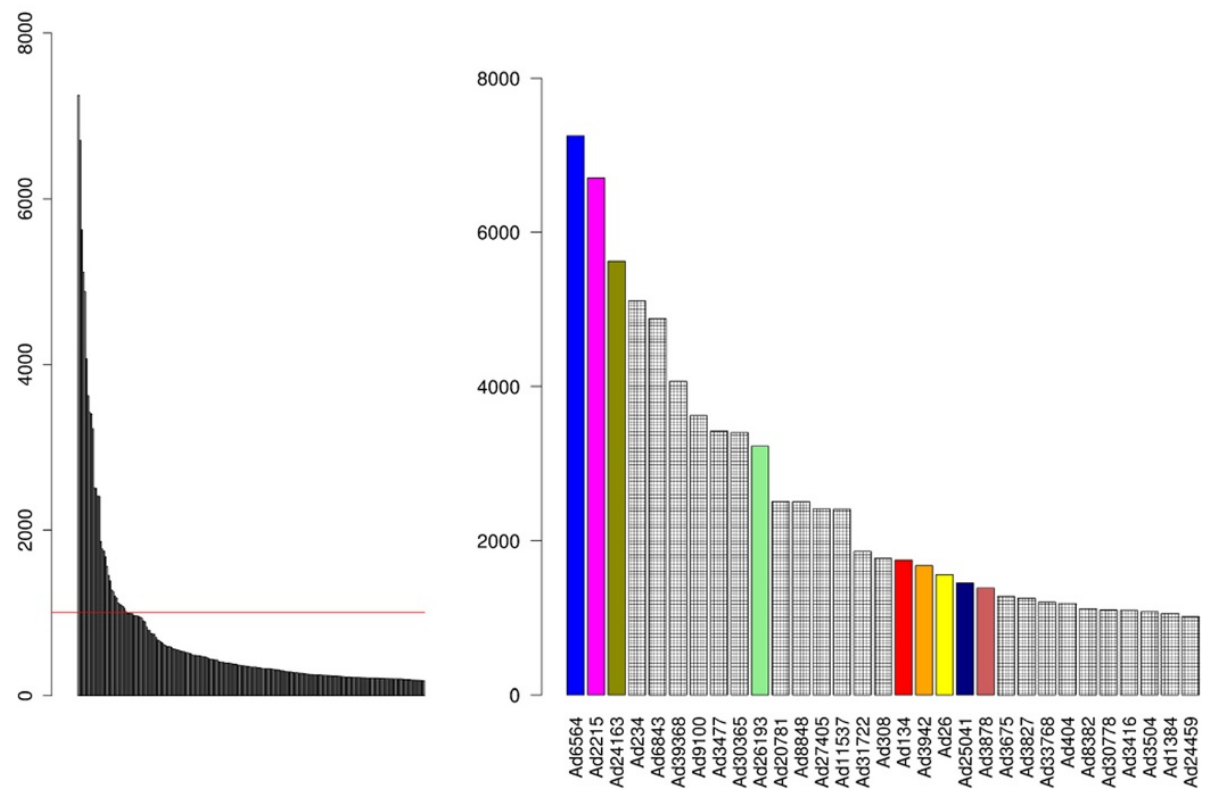

Figure 5 Distribution of miRNAs in newborn and adult venom gland transcriptomes. Left, uneven distribution of the number of miRNAs identified in the venom gland transcriptomes of newborn (upper panel) and adult (lower panel). The red line marks the 1000 copy threshold. Right, Comparison of highly expressed (>1000 counts) venom gland miRNAs in newborn (upper panel) and adult (lower panel) C. s. simus datasets. Bars corresponding to miRNAs shared between newborn and adult transcriptomes are filled with the same color. For details of the expression profile of highly expressed miRNAs in the venom gland transcriptome, and their newborn to adult expression ratios, please consult Tables S4 and S5 (Additional File 1).

caveat of our current understanding of miRNA target recognition and post-transcriptional venom gland transcriptome regulation is the absence of mapeable snake genomes. Nonetheless, almost half of the most abundant miRNAs sequenced from the venom gland of both, newborn and adult, C. s. simus were orthologous to sequences in $A$. carolinensis. More significant is the fact that a $C$. s. simus newborn venom gland-exclusive miRNA and a venom gland miRNA uniquely found in adult snakes target, respectively, mRNAs encoding a PIII-SVMP and the B-subunit of crotoxin/Mojave toxin. Relevant to this point, Mojave toxin is a neurotoxic heterodimeric $\mathrm{PLA}_{2}$, whose translation into the venom proteome is ontogenetically regulated [29] (Figure 1). 


\begin{tabular}{|c|c|c|c|c|c|}
\hline \multicolumn{2}{|l|}{ Cluster ID } & miRNA Sequence & $\begin{array}{l}\text { Adult }_{\text {SV }} \\
\text {. }\end{array}$ & $\begin{array}{l}\text { Newborn } \\
\text { MP }\end{array}$ & $\begin{array}{l}\text { Adult } \\
\text { PLA }_{2}\end{array}$ \\
\hline New 752 & & AGCTGAAGAGGAAAACAACACTTTCCTTAGTGACA & $\mathrm{X}^{1}$ & $\mathrm{X}^{1}$ & \\
\hline New 253 & & AGCTGAAGAGGAAAACAACACTTTCCTTAGTGACCA & $\mathrm{X}^{1}$ & $\mathrm{X}^{1}$ & \\
\hline New 3503 & & GCATTGGTGGTTCAGTGGTAGAATTCTCGCC & & $X^{1}$ & \\
\hline New 2681 & & AGCAGCTGACTTAGAACTGGCGCGGA & $x^{1}$ & $\mathrm{x}^{\prime}$ & \\
\hline Ad 368 & New299 & ATGGCCTCCGTCGCCCTCAGCCGATCGA & & & $X^{1,2}(181) \quad X^{1,2}(186)$ \\
\hline Ad 1078 & New1849 & ACGTGCAAATCGGTCGTCCGACCTGGGTA & & & $X^{1,2}(113) X^{1,2}(105)$ \\
\hline New 20 & & TGATCCTTCGATGTCGGCTCT & & $x^{1}$ & \\
\hline New & & 3708 GCGTTGGTGGTATAGTGGTGAGCATAGC & & $\mathrm{X}^{1}$ & \\
\hline New 87 & & GAGGTAAACGGGTGGGGTCCGCGCA & $\mathrm{X}^{1}$ & $\mathrm{X}^{1}$ & \\
\hline New 4393 & Ad3416 & GCGTTGGTGGTATAGTGGTTAGCATAGC & $X^{1,2}(1092)$ & $\mathbf{X}^{1,2}(496)$ & \\
\hline New 166 & & AAGAGGTAAACGGGTGGGGTCCGCGC & $\mathrm{X}^{1}$ & $x^{1}$ & \\
\hline New 2578 & & GGATGGGAGACCGCCTGGGAATACCGGGTGCTGT & & $\mathrm{X}^{1,2}(\mathbf{1 1 8 5 )}$ & \\
\hline Ad 2166 & & CGAGGCGTCCAGTGCGGTAACGCGAC & & & $\mathrm{X}^{1,2}(590)$ \\
\hline
\end{tabular}

Figure 6 miRNA sequences predicted by miRanda (1) and MapMi (2) to target 3'-UTR loci of SVMP (blue) and PLA2 (red) transcripts. miRNA counts in their respective transcriptome are indicated in parentheses. Best BLAST hits of the clusters mapped by the miRanda- and MapMi-predicted miRNAs are listed in Figure 7. Best BLAST hits for miRanda-only-predicted miRNA sequences are displayed in Additional file 2: Table S6.

The noncovalent association of two dissimilar subunits, the small acidic, nonenzymatic, and nontoxic A-subunit with the basic and weakly toxic $\mathrm{PLA}_{2}$ B-subunit increases the lethal potency of the uncomplexed crotoxin B-subunit by enabling the toxin to reach its specific site of action at the neuromuscular junction [40,41,89-91]. Hence, miRNAs targeting a crotoxin subunit messenger would serve the goal of eliminating the generation of the neurotoxic heterodimer. Age-dependent changes in the concentration of miRNA modulating the transition from a crotoxin-rich to a SVMP-rich venom from birth through adulthood can potentially explain what is observed in the age-dependent proteomic analysis of the ontogenetic changes in the venom composition of $C . s$. simus illustrated in Figure 1.

Large-scale proteomic analysis, performed for one miRNA (miR-223) in only one cell type (murine neutrophils), revealed that although some proteins were repressed by $50-80 \%$, miR-223 typically had more modest effects [92], suggesting that perhaps other miRNAs in their endogenous context have targets for which protein output is more dramatically repressed. Clearly, a challenge ahead in molecular toxinology is to design laboratory experiments to uncover the impact, molecular details, and evolution of the regulatory miRNA-target interactions that shape venom phenotype during snake development. In this regard, it has been proposed that a single origin of venom in Squamata, the order of reptiles including lizards and snakes, dates back roughly 200 Mya to the Late Triassic/Early Jurassic period [1,2,93]. Existing snake venom toxins are the result of recruitment events by which ordinary genes were duplicated, and the new genes selectively expressed in the venom gland and amplified to multigene families with extensive neofunctionalization throughout the approximately $112-$ 125 Mya of snake evolution. Given the central role that diet has played in the adaptive radiation of snakes [4], venom thus represents a key adaptation that has played an important role in the diversification of snakes. Our findings here reported support the view that understanding the basis for the phenotypic diversity of snake venoms requires a deep understanding of the mechanisms regulating the transcriptional and translational activity of the venom gland. Our results, though restricted

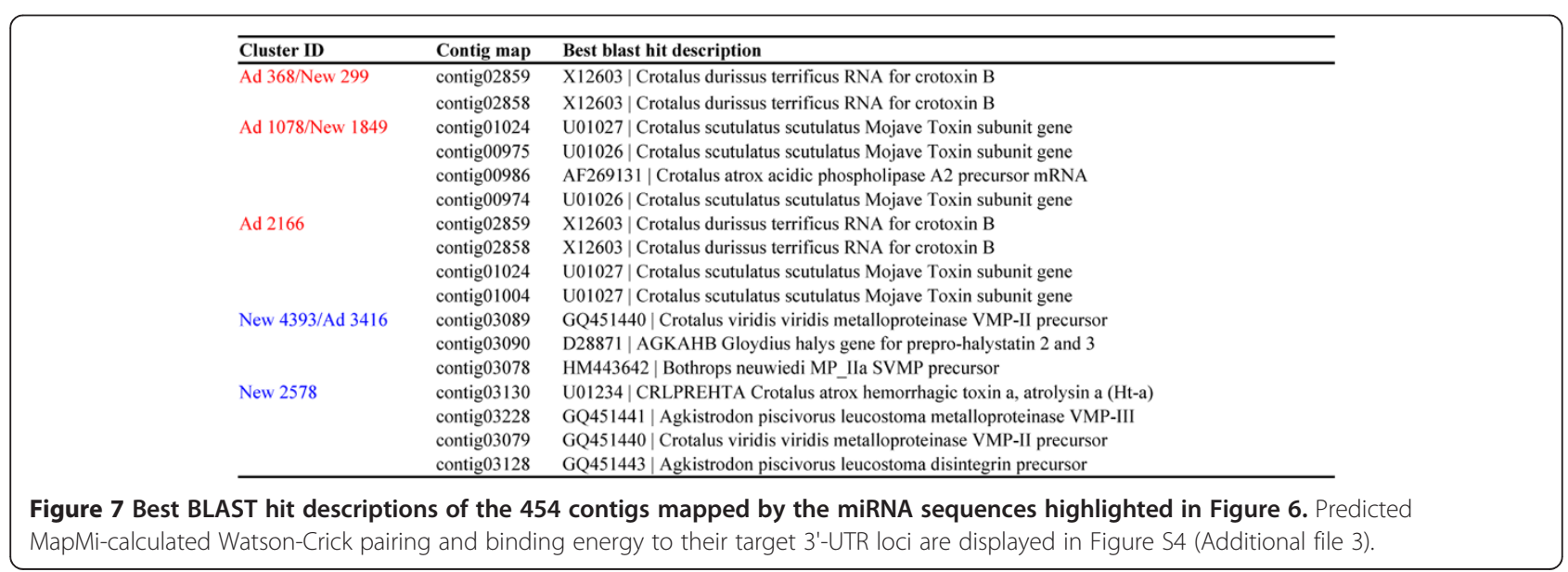




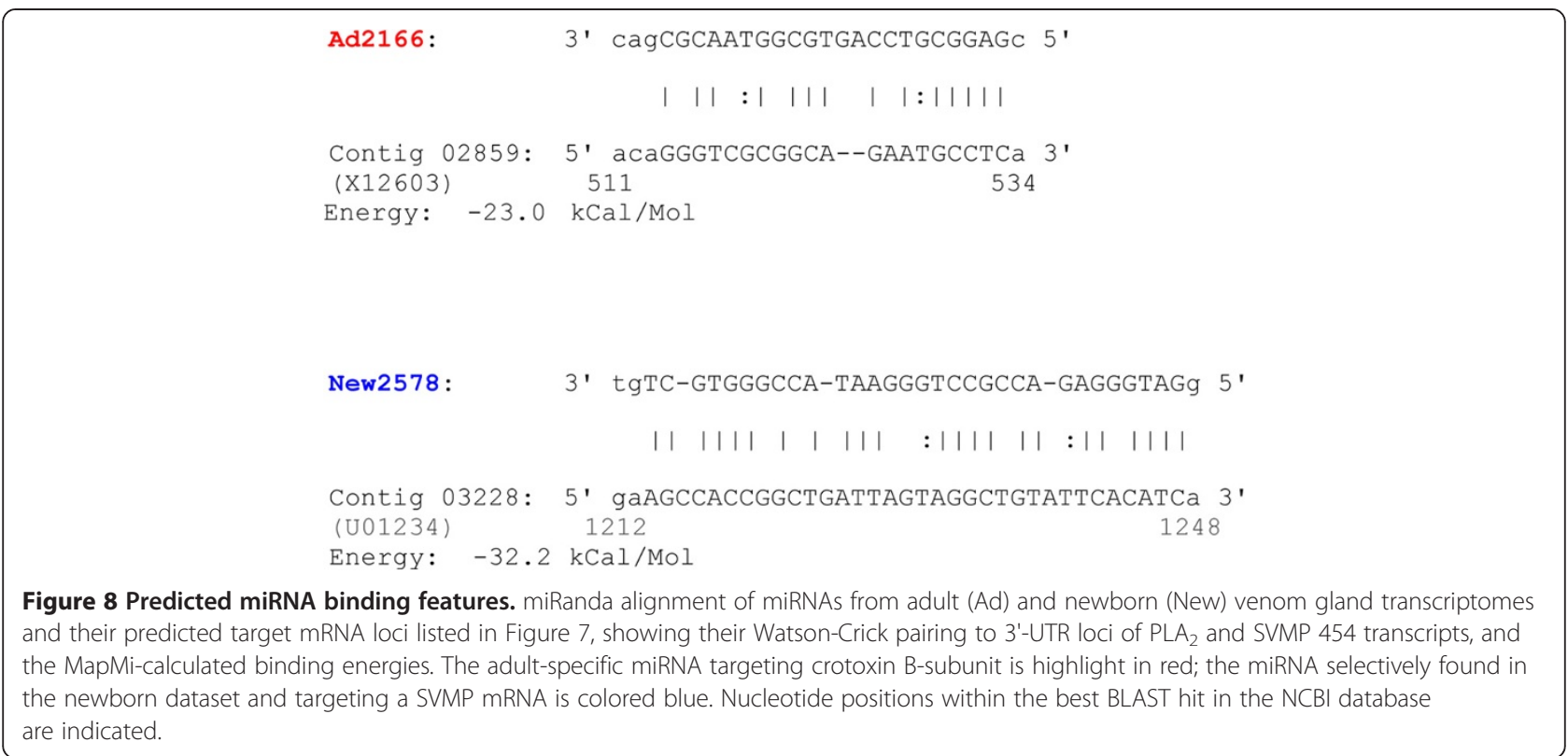

to individual specimens from a single species, suggest a functional role for miRNAs. The impact of specific miRNAs in the modulation of venom composition, and the integration of the mechanisms responsible for the generation and impact of these miRNAs on patterns of expression in the snake's venom gland, are further challenges for future research.

\section{Methods \\ Proteomics assessment of the ontogenetic shift of venom composition in C. simus}

Venoms from a large number (>25) of adult Crotalus $s$. simus specimens and from 11 captive-born siblings (from an age of 8-weeks to 21-months) kept at the serpentarium of the Instituto Clodomiro Picado, University of Costa Rica in San José were collected by snake biting on a parafilm-wrapped jar (adults and juveniles) or by aspiration from the fangs of neonates using an Eppendorf pipette. Crude venoms were centrifuged at low speed to remove cells and debris, lyophilized, weighed on a microbalance, and stored at $-20^{\circ} \mathrm{C}$ until used. Venom proteins were separated by reverse-phase HPLC using a Teknokroma Europa $\mathrm{C}_{18}(0.4 \mathrm{~cm} \times 25$ $\mathrm{cm}, 5 \mathrm{~mm}$ particle size, $300 \AA$ pore size) column and an Agilent LC 1100 High Pressure Gradient System equipped with DAD detector and micro-Auto-sampler. The flow-rate was set to $1 \mathrm{ml} / \mathrm{min}$ and the column was developed with a linear gradient of $0.1 \%$ TFA in water (solution A) and acetonitrile (solution B), isocratically (5\% B) for $10 \mathrm{~min}$, followed by $5-25 \%$ B for $20 \mathrm{~min}, 25-$ $45 \% \mathrm{~B}$ for $120 \mathrm{~min}$, and $45-70 \%$ for $40 \mathrm{~min}$. Isolated proteins were characterized as described [29].
Snake venom gland cDNA synthesis and 454 sequencing

Venom glands of an 8-week-old and an adult C. s. simus specimens were removed 3 days after venom milking, when transcription is maximal [94], from anesthetized snakes using fine forceps and immediately placed in RNAlater $^{\mathrm{TM}}$ solution (Qiagen). About $50 \mathrm{mg}$ of tissue were disrupted and homogenized by a rotor-stator homogenizer, and total RNA was isolated using RNeasy Mini kit (Qiagen), quantified in a NanoDrop ND_spectrophotometer (NanoDrop Technologies, Wilmington, DE, USA) through the A260/A280 ratio, and quality-checked on an agarose gel discerning the $28 \mathrm{~S}$ and $18 \mathrm{~S}$ bands of ribosomal RNA. First strand cDNA was synthesized using RevertAid ${ }^{\mathrm{TM}} \mathrm{H}$ Minus First Strand cDNA Synthesis Kit (Fermentas), which selectively transcribes full-length polyadenylated mRNA. The manufacturer's recommendations were followed except where specified. Approximately $5 \mu \mathrm{g}$ of total RNA was used as starting material. In order to avoid polymerase slippage, a modified 3' 54-mer adaptor (5' GAGCTAGT TCTGGAG(T) ${ }_{16} \mathrm{VN}$ ), which includes a type IIs enzyme (GsuI) site (underlined), was used for first-strand synthesis. This modified oligonucleotide effectively converts the long run of adenosine residues at the polyA tail into a sequence that causes fewer problems for dideoxy sequencing chemistry, and thus the resulting cDNA libraries were enriched in 3'-end-transcripts. To avoid internal cuts, the cDNA was hemimethylated by adding 5-methyl-dCTP to the dNTPs mix. The first strand cDNA was used as template for second strand synthesis by E. coli DNA Polymerase I and RNase H. Double strand (ds) cDNA was precipitated with ethanol and the pellet was resuspended in $70 \mu \mathrm{L}$ of nuclease-free water 
and subjected to enzymatic digestion with GsuI for 4 hours at $30^{\circ} \mathrm{C}$. The enzyme was then inactivated at $65^{\circ} \mathrm{C}$ for 20 minutes and the digested cDNA was stored at $-20^{\circ} \mathrm{C}$. For 454 pyrosequencing, the GS FLX General DNA Library Preparation Method Manual workflow (Roche Diagnostics) was followed. To this end, $3 \mu \mathrm{g}$ of final non-normalized cDNA library were sheared by nebulization into small fragments. The fragment ends were polished and short A/B adaptors were ligated onto both ends, providing priming regions to support both emulsion amplification and the pyrosequencing process. A biotin tag on the $\mathrm{B}$ adaptor allowed immobilization of the dscDNA library fragments onto streptavidinconjugated magnetic beads and the subsequent isolation of the library of single strand cDNA sequencing templates. Each of the eight cDNA libraries was tagged with a unique 10-base sequence (MID, Multiplex IDentifier) that is recognized by the sequencing analysis software, allowing for automated sorting of MID-containing reads. Barcoded libraries were simultaneously sequenced in a Genome sequencing FLX Titanium System (Roche Applied Science) at Life Sequencing S.L. (Parc Científic Universitat de Valencia, Paterna, Valencia, Spain; http:// www.lifesequencing.com) using the method developed by Margulies et al. [95].

\section{Bioinformatic analysis of the $\mathbf{4 5 4}$ reads}

454 data were analyzed using the workflow developed in [15] to identify sequences of toxin molecules by similarity search against nucleotide databases, which includes available NGS algorithms and in-house scripts. An initial quality test step of both the raw reads provided by the Genome Sequencer FLX System prior to the assembly process and the longer contig sequences obtained after running the 454 Newbler assembler program (version 2.6) (Titanium chemistry) was run using the Prinseq program (standalone version 0.17.4) [96]. Interspersed repeats and low complexity DNA sequences were masked from the transcript reads using RepeatMasker (version 3.2.9) [97]. RepeatMasker is available from the Institute for Systems Biology (http://www.systemsbiology.org) addressing http://repeatmasker.org. The program screens DNA sequences for interspersed repeats and low complexity DNA sequences included in the Repbase database (http://www.girinst.org). Repbase, a comprehensive database of repetitive element consensus sequences (update of 20 September 2011), operates as a service of the Genetic Information Research Institute (http://www.girinst.org). Data and computational resources for the Pre-Masked Genomes page is provided courtesy of the UCSC Genome Bioinformatics group (http://genome.ucsc.edu). Masked contig sequences were translated into the 6 possible reading frames and blasted against the non-redundant NCBI database (http://blast.ncbi.nlm.nih.gov, release of February
2012) and the UniProtKB/Swiss-Prot Toxin Annotation Program database (http://us.expasy.org/sprot/tox-prot), using BlastX and BlastN [98] algorithms (version 2.2.24), specifying a cut-off value of e-03 and BLOSUM62 as scoring matrix. Snake venom gland-specific transcripts were selected from best BLAST-hit descriptions identifying GenBank entries belonging to the taxonomic suborder Serpentes. This taxonomic group is represented by 44,141 nucleotide records comprising entries from 2,396 different species. A second filtering round was carried out using a list of keywords (including the acronyms of all known toxin protein families described so far to distinguish putative snake venom toxins from non-toxin (ribosomal, mitochondrial, nuclear, etc.) ordinary proteins [15]. The phylogenetically nearest tophit full-length sequence was designated as the reference sequence onto which all toxin family-specific reads were aligned to create a multiple alignment using COBALT [99]. The multiple alignment was then parsed to create an assembled (consensus) toxin sequence in which each amino acid position is supported by at least four reads. We considered two contigs as different if their nucleotide sequences depart in more number of positions than expected from a sequencing error rate of $1.5 \%$, and the same mutated residues were found in at least two other reads. Positions where two or more amino-acids fulfilled this criterium were annotated as variable residues suggesting the occurrence of different alleles (isoforms) of the protein.

The relative expression of a given toxin protein family was calculated according to the RPKM (Reads per Kilobase of exon per Million mapped reads) standard procedure described by Mortazavi and coworkers [100]. This normalization procedure provides an analog of the relative molar concentrations of transcripts. To this end, all the reads contributing to the contigs (regardless whether that read uniquely maps to that contig or not) and the length of the phylogenetically nearest coding sequence were taken into account to calculate the RPKM normalized figure:

$$
\mathrm{RPKM}=\frac{\text { ORF reads }+ \text { ORF Singletons }}{\frac{\text { Total reads }}{10^{6}} \times \frac{\text { Length }}{10^{3}}}
$$

Possible differential expression of venom proteins between adult and the newborn individuals was assessed with the non-parametric NOISeq-sim algorithm [101] using the following parameters recommended for counts without replicates in the NOISeq-sim manual were used: $\mathrm{k}$ (counts equal to zero) $=0.5$; nss (number of samples to be simulated) $\geq 5$; pnr (percentage of the total 
sequencing depth) $=0.2 ; \mathrm{v}$ (variability in the total sequencing depth of the simulated sample) $=0.02$. Reads were normalized by the length of the phylogenetically nearest sequence and a threshold of 0.9 was allowed.

\section{Comparison of newborn and adult C. s. simus venom transcriptomes}

To assess the degree of similarity between transcripts synthesized by newborn an adult venom glands, a Perl script was written that aligned singletons and Newblerassembled contigs onto the open reading frame (ORF) of the phylogenetically nearest protein sequence used as reference. The aligned nucleotide sequences were re-assembled with MIRA (http://www.chevreux.org/ projects_mira.html) to infer the minimum number of different assemblies. These resulting sequences from newborn and adult individuals were compiled into a single FASTA file, translated into protein sequences, and manually inspected to discard possible mispaired BLAST annotations of local regions due to incorrect frame translations. Protein sequences were then clustered with CD-HIT (standalone version 4.5 .7 built on 27th February 2012) [102,103] to identify protein sequences shared between newborn and adult transcriptomes.

\section{Snake venom gland microRNA profiling}

Total RNA from neonate and adult venom glands was used to isolate small RNA libraries using a RNeasy Mini Kit following the manufacture's (Qiagen) instructions. Samples were quantified using a NanoDrop ND-1000 spectrophotometer (NanoDrop Technologies, Wilmington, DE, USA) through the $260 / 280$ absorbance relation. 5 microliter of neonate (258.6 ng/microliter) and adult (490.7 ng/microliter) size (<200 nt)-enriched microRNA (miRNA) library were sequenced on an Ion Torrent Personal Genome Machine $\left(\mathrm{PGM}^{\mathrm{T}}\right)$ Sequencing platform at Life Sequencing S.L.

\section{Bioinformatic processing of the lon-Torrent miRNA reads}

Using Prinseq [96], the Ion-Torrent miRNA reads were filtered out according to nucleotide length (min_length $15 \mathrm{nt}$; max_length $40 \mathrm{nt}$ ) and the presence of either the 30-mer IonA or the 23-mer P1 adapter sequences. Adapter sequences were removed using the fasxt_clipper tool from the Fastx-Toolkit (http://hannonlab.cshl.edu/ fastx_toolkit). The resulting reads were clustered using CD-HIT-454 [102] setting an identity threshold of 0.98 and the accurate mode option g1. HIT-454 was designed to identify artificial duplicates from raw 454 sequencing reads, including exact duplicates and near identical duplicates. Script cdhit-cluster-consensus (v.13) of the CD-HIT suite of programs was run to derive consensus sequences for each of the miRNA clusters. This program is currently maintained by Dr. Li's group (http://weizhong-lab.ucsd.edu). The relative abundances of miRNAs with frequency count $\geq 100$ were normalized by scaling the number of reads clustered by CD-HIT-454 to the total number of processed reads $(220,548$ for newborn $+389,064$ for adult). To identify unique and shared sequences between the newborn and adult datasets, these newborn and adult miRNA clusters were compared between themselves using CD-HIT. Differential expression between miRNAs in these two datasets was assessed with NOISeq-sim [101] allowing a threshold of 0.9 . miRNAs comprising $\geq 100$ reads were subjected to BLAST analysis against miRBase (release 18, November 2011, which included 21643 mature miRNA products from 168 species) (http://www.mirbase.org) [79].

\section{The search for miRNA targets}

The precise rules and energetics for pairing between a miRNA and its mRNA target sites are not completely understood [104,105]. A variety of computational algorithms aimed at predicting miRNA target genes incorporate rules for miRNA-mRNA interactions such as base pairing complementarity and favourable miRNA-mRNA duplex thermodynamics. Current prediction methods are diverse, both in approach and performance [106]. We have employed the freely available target prediction, position-weighted local alignment miRanda algorithm (standalone version 3.3a) [80,81] and the MapMi webserver (version 1.5.0-build 01, release March 2012) (http://www.ebi.ac.uk/enright-srv/MapMi) [83] to identify candidate miRNA target sites in 3'-UTR regions of 454 reads by base complementarity, and putative miRNA loci, respectively. MapMi is a tool designed to locate miRNA precursor sequences in existing genomic sequences, using potential mature miRNA sequences as input. miRanda is an algorithm for finding genomic targets for microRNAs that incorporates current biological knowledge on target rules and computes optimal sequence complementarity between a set of mature microRNAs and a given mRNA using a weighted dynamic programming algorithm. In addition, miRanda uses an estimate of the free energy of formation of the miRNA:mRNA duplex as a secondary filter [82]. The following parameters were set to reduce the estimated false positives to $\leq 9 \%[80,81]$ : total Score $>100 ; \Delta G$ of the intermediate duplex $<-19 \mathrm{Kcal} / \mathrm{mol}$; and output of 2 or more 454-contig targets.

\section{Database accession}

The raw 454 GS FLX Titanium reads of C. s. simus adult and neonate venom gland transcriptomes, and the Ion Torrent PGM reads (miRNA sequences) of adult and neonate $C$. s. simus have been archived as Standard Flowgram Format (sff) files with the NCBI Sequence 
Read Archive (SRA) (http://www.ncbi.nlm.nih.gov/sra? term=SRA051956) under accession codes SRX143982 and SRX143985, SRX143983 and SRX143984, respectively.

\section{Animal ethics}

Procedures for snake maintenance, sacrifice, and gland extraction in this study followed the Quality Management Protocols from the Instituto Clodomiro Picado, University of Costa Rica, and comply the Animal Welfare Law \#7451, chapters II and III, and the Biodiversity Law, Decree 7788, Republic of Costa Rica. Research permission was allowed under Resolution ACG- SINAC- PI-012-2010 (Ministry of Environment of Costa Rica).

\section{Additional files}

Additional file 1: Table S1. RepeatMasker usage results and features of the sequence elements masked in the adult C. s. simus venom gland transcriptomes analyzed. Table S2. RepeatMasker usage results and features of the sequence elements masked in the adult C. s. simus venom gland transcriptomes analyzed.

Additional file 2: Table S3. Relative abundances of the different venom protein family hits in the venom gland transcriptomes of newborn and adult C. s. simus. Table S4. NoiSeq computed expression profile of highly expressed (>100 counts) miRNAs in the venom gland transcriptome listed by decreasing newborn $(N)$ to adult $(A)$ expression ratio. Table S5. NoiSeq computed expression profile of highly expressed (>100 counts) miRNAs in the venom gland transcriptome listed by decreasing adult (A) to newborn ( $\mathrm{N}$ ) expression ratio. Table S6. MiRanda predicted miRNAs complementary of 3'-UTR loci of 454 C. s. simus venom transcripts.

Additional file 3: Figure S1. Multiple alignment of transcript-deduced amino acid sequences of PLA 2 molecules. Figure S2. Multiple alignment of transcript-deduced serine proteinase amino acid sequences. Figure S3. Multiple alignment of transcript-deduced amino acid sequences of snake venom metalloproteinases. Figure S4. Predicted targets for the miRNAs displayed in Figure 7, showing their Watson-Crick pairing to target 3'-UTR loci of PLA 2 and SVMP 454 transcripts, and the corresponding binding energy calculated by MapMi.

\section{Competing interests}

The authors declare that they have no competing interests

\section{Authors' contributions}

$A G, F B, S R$ and $D C$ were responsible for all stages of animal care and venom extraction. FB, MS and AG dissected the venom glands. AP and LS prepared the RNA samples for 454 and lon Torrent sequencing. All co-authors (JD, AP, $L S, A G, F B, S R, D C, M S, Y A, J M G, J J C$ ) analyzed the data and participated in data interpretation and discussion of the results, as well as in revising the article drafted by JJC. All co-authors have seen, reviewed, and approved the final version of the manuscript.

\section{Acknowledgements}

This work has been financed by grant BFU2010-17373 from the Ministerio de Economía y Competitividad, Madrid, Spain; PROMETEO/2010/005 from the Generalitat Valenciana; and projects 741-B2-093 from the Vicerrectoría de Investigación, Universidad de Costa Rica, CRUSA-CSIC (2009CR0021), and CYTED (206AC0281). We also acknowledge support of the publication fee by the CSIC Open Access Publication Support Initiative through its Unit of Information Resources for Research (URICI). JD is grateful to Eva Alloza (CIPF) and José Afonso Guerra-Assunçâo (EBI) for useful comments and advice regarding miRNA sequence analysis.

\section{Author details}

${ }^{1}$ Instituto de Biomedicina de Valencia, Consejo Superior de Investigaciones Científicas, Jaime Roig 11, Valencia 46010, Spain. ${ }^{2}$ Instituto Clodomiro Picado, Facultad de Microbiología, Universidad de Costa Rica, San José, Costa Rica.

Received: 12 November 2012 Accepted: 14 March 2013 Published: 10 April 2013

\section{References}

1. Fry BG, Vidal N, Norman JA, Vonk FJ, Scheib H, Ramjan SF, Kuruppu S, Fung K, Hedges SB, Richardson MK, Hodgson WC, Ignjatovic V, Summerhayes R, Kochva E: Early evolution of the venom system in lizards and snakes. Nature 2006, 439:584-588.

2. Fry BG, Casewell NR, Wüster W, Vidal N, Young B, Jackson TN: The structural and functional diversification of the Toxicofera reptile venom system. Toxicon 2012, 60:434-448,

3. Vonk FJ, Admiraal JF, Jackson K, Reshef R, de Bakker MA, Vanderschoot K, van den Berge I, van Atten M, Burgerhout E, Beck A, Mirtschin PJ, Kochva E, Witte F, Fry BG, Woods AE, Richardson MK: Evolutionary origin and development of snake fangs. Nature 2008, 454:630-633.

4. Greene HW: Dietary correlates of the origin and radiation of snakes. Am Zool 1983, 23:431-441.

5. Daltry JC, Wüster W, Thorpe RS: Diet and snake venom evolution. Nature 1996, 379:537-540.

6. Gibbs HL, Mackessy SP: Functional basis of a molecular adaptation: prey-specific toxic effects of venom from Sistrurus rattlesnakes. Toxicon 2008, 53:672-679.

7. Barlow A, Pook CE, Harrison RA, Wüster W: Coevolution of diet and prey-specific venom activity supports the role of selection in snake venom evolution. Proc Biol Sci 2009, 276:2443-2449.

8. Vidal N, Hedges SB: The molecular evolutionary tree of lizards, snakes, and amphisbaenians. C Rendus Biol 2009, 332:129-139.

9. Vidal N, Rage J-C, Couloux A, Hedges SB: Snakes (Serpentes). In The Timetree of Life. Edited by Hedges SB, Kumar S. Oxford Univ. Press; 2009:390-397.

10. Redi F: In Osservazioni Intorno alle Vipere. Edited by All'Insegna Della Stella F.; 1664. a digitalized version is freely accessible in http://archive.org/details/ osservazioniint00redigoog.

11. Fontana F: Traité sur le vénin de la vipere, sur les poisons amaricains, sur le laurier-cerise et sur quelques autres poisons végetaux. Florence: Gibelin; 1781

12. Hawgood BJ: Abbé Felice Fontana (1730-1805): founder of modern toxinology. Toxicon 1995, 33:591-601

13. Calvete JJ: Venomics, what else? Toxicon 2012, 60:427-433.

14. de Azevedo ILM J, Diniz MRV, Ho PL: Venom gland transcriptomic analysis. In Animal Toxins: State of the Art. Perspectives in Health and Biotechnology. Edited by De Lima ME, Pimenta AMC, Martin-Euclaire MF, Zingali RB, Rochat H. Belo Horizonte: Editora UFMG; 2009:693-713.

15. Durban J, Juárez P, Angulo Y, Lomonte B, Flores-Diaz M, Alape-Girón A, Sasa M, Sanz L, Gutiérrez JM, Dopazo J, Conesa A, Calvete JJ: Profiling the venom gland transcriptomes of Costa Rican snakes by 454 pyrosequencing. BMC Genomics 2011, 12:259.

16. Rokyta DR, Wray KP, Lemmon AR, Lemmon EM, Caudle SB: A high-throughput venom-gland transcriptome for the Eastern Diamondback Rattlesnake (Crotalus adamanteus) and evidence for pervasive positive selection across toxin classes. Toxicon 2011, 57:657-671.

17. Calvete JJ: Proteomic tools against the neglected pathology of snake bite envenoming. Exp Rev Proteomics 2011, 8:739-758.

18. Calvete JJ: Snake venomics: from the inventory of toxins to biology. Toxicon 2013. in press.

19. Fry BG, Roelants K, Champagne DE, Scheib H, Tyndall JD, King GF, Nevalainen TJ, Norman JA, Lewis RJ, Norton RS, Renjifo C, de la Vega RC: The toxicogenomic multiverse: convergent recruitment of proteins into animal venoms. Annu Rev Genomics Hum Genet 2009, 10:483-511.

20. Fry BG, Scheib H, De LM, Junqueira De Azevedo I, Silva DA, Casewell NR: Novel transcripts in the maxillary venom glands of advanced snakes. Toxicon 2012, 59:696-708.

21. Chippaux JP, Williams V, White J: Snake venom variability: methods of study, results, and interpretation. Toxicon 1991, 29:1279-1303. 
22. Gibbs HL, Sanz L, Calvete JJ: Snake population venomics: proteomics-based analyses of individual variation reveals significant gene regulation effects on venom protein expression in Sistrurus rattlesnakes. J Mol Evol 2009, 68:113-125.

23. Gibbs HL, Sanz L, Chiucchi JE, Farrell TM, Calvete JJ: Proteomic analysis of ontogenetic and diet-related changes in venom composition of juvenile and adult Dusky Pigmy rattlesnakes (Sistrurus miliarius barbouri). J Proteomics 2011, 74:2169-2179.

24. Chiucchi JE, Gibbs HL: Similarity of contemporary and historical gene flow among highly fragmented populations of an endangered rattlesnake. Mol Ecol 2010, 19:5345-5358.

25. Mackessy SP: Venom ontogeny in the Pacific rattlesnakes, Crotalus viridis helleri and C. viridis oreganus. Copeia 1988, 1988:92-101.

26. Guércio RAP, Shevchenko A, Shevchenko A, López-Lozano JL, Paba J, Sousa MV, Ricart CAO: Ontogenetic variations in the venom proteome of the Amazonian snake Bothrops atrox. Proteome Sci 2006, 4:11.

27. Mackessy SP, Sixberry NM, Heyborne WH, Fritts T: Venom of the Brown Treesnake, Boiga irregularis: ontogenetic shifts and taxa-specific toxicity. Toxicon 2006, 47:537-548.

28. Alape-Girón A, Sanz L, Escolano J, Flores-Díaz M, Madrigal M, Sasa M, Calvete JJ: Snake venomics of the lancehead pitviper Bothrops asper: geographic, individual, and ontogenetic variations. J Proteome Res 2008, 7:3556-3571.

29. Calvete JJ, Sanz L, Cid P, De La Torre P, Flores-Diaz M, Dos Santos MC, Borges A, Bremo A, Angulo Y, Lomonte B, Alape-Girón A, Gutiérrez JM: Snake venomics of the Central American rattlesnake Crotalus simus and the South American Crotalus durissus complex points to neurotoxicity as an adaptive paedomorphic trend along Crotalus dispersal in South America. J Proteome Res 2010, 9:528-544.

30. Zelanis A, Travaglia-Cardoso SR, Furtado MFD: Ontogenetic changes in Bothrops insularis (Serpentes: Viperidae) snake venom and its biological implications. South Am J Herpetol 2008, 3:45-50.

31. Zelanis A, Tashima AK, Pinto AF, Leme AF, Stuginski DR, Furtado MF, Sherman NE, Ho PL, Fox JW, Serrano SM: Bothrops jararaca venom proteome rearrangement upon neonate to adult transition. Proteomics 2011, 11:4218-4228.

32. Madrigal M, Sanz L, Flores-Diaz M, Sasa M, Núñez V, Alape-Girón A, Calvete JJ: Snake venomics across genus Lachesis. Ontogenetic changes in the venom composition of $L$. stenophrys and comparative proteomics of the venoms of adult $L$. melanocephala and L. acrochorda. J Proteomics. in press.

33. Andrade DV, Abe AS: Relationship of venom ontogeny and diet in Bothrops. Herpetologica 1999, 55:200-204.

34. Wüster W, Ferguson JE, Quijada-Mascareñas JA, Pook CE, Salomão MG, Thorpe RS: Tracing an invasion: landbridges, refugia and the phylogeography of the Neotropical rattlesnake (Serpentes: Viperidae: Crotalus durissus). Mol Ecol 2005, 14:1095-1108.

35. Gutiérrez JM, Dos Santos MC, Furtado MF, Rojas G: Biochemical and pharmacological similarities between the venoms of newborn Crotalus durissus durissus and adult Crotalus durissus terrificus rattlesnakes. Toxicon 1991, 29:1273-1277.

36. Saravia P, Rojas E, Arce V, Guevara C, López JC, Chaves E, Velásquez R, Rojas G, Gutiérrez JM: Geographic and ontogenic variability in the venom of the neotropical rattlesnake Crotalus durissus: Pathophysiological and therapeutic implications. Rev Biol Trop 2002, 50:337-346.

37. Mackessy SP: Venom composition in rattlesnakes: trends and biological significance. In The Biology of Rattlesnakes. Edited by Hayes WK, Beaman KR, Cardwell MD, Bush SP. Loma Linda, California: Loma Linda University Press; 2008:495-510.

38. Mackessy SP: Evolutionary trends in venom composition in the Western Rattlesnakes (Crotalus viridis sensu lato): Toxicity vs. tenderizers. Toxicon 2010, 55:1463-1474.

39. McCue MD: Cost of producing venom in three North American pitviper species. Copeia 2006, 2006:818-825.

40. Bon C: Multicomponent neurotoxic phospholipases $A_{2}$. In Venom phospholipase A2 enzymes: structure, function and mechanism. Edited by Kini RM. Chichester: Wiley; 1997:269-286.
41. Faure $G, X u H$, Saul FA: Crystal structure of crotoxin reveals key residues involved in the stability and toxicity of this potent heterodimeric $\beta$ neurotoxin. J Mol Biol 2011, 412:176-191.

42. Faure $G$, Saul F: Crystallographic characterization of functional sites of crotoxin and ammodytoxin, potent $\beta$-neurotoxins from Viperidae venom. Toxicon 2012, 60:531-538.

43. Gutiérrez JM: Clinical toxicology of snakebite in Central America. In Handbook of clinical toxicology of animal venoms and poisons. Edited by Meier J, White J. Boca Raton, Florida: CRC; 1995:645-665.

44. Massey DJ, Calvete JJ, Sánchez EE, Sanz L, Richards K, Curtis R, Boesen K: Venom variability and envenoming severity outcomes of the Crotalus scutulatus scutulatus (Mojave rattlesnake) from Southern Arizona. J Proteomics 2012, 75:2576-2587.

45. Glenn JL, Sraight RC, Wolfe MC, Hardy DL: Geographical variation in Crotalus scutulatus scutulatus (Mojave rattlesnake) venom properties. Toxicon 1983, 21:119-130.

46. Glenn JL, Sraight RC: Intergradation of two different venom populations of the Mojave rattlesnake (Crotalus scutulatus scutulatus) in Arizona. Toxicon 1989, 27:411-418.

47. Gutiérrez JM, Lomonte B, León G, Alape-Girón A, Flores-Díaz M, Sanz L, Angulo Y, Calvete JJ: Snake venomics and antivenomics: Proteomic tools in the design and control of antivenoms for the treatment of snakebite envenoming. J Proteomics 2009, 72:165-182

48. Williams DJ, Gutiérrez JM, Calvete JJ, Wüster W, Ratanabanangkoon K, Paiva O, Brown NI, Casewell NR, Harrison RA, Rowley PD, O'Shea M, Jensen SD, Winkel KD, Warrell DA: Ending the drought: new strategies for improving the flow of affordable, effective antivenoms in Asia and Africa. J Proteomics 2011, 74:1735-1767.

49. Huse SM, Huber JA, Morrison HG, Sogin ML, Welch DM: Accuracy and quality of massively parallel DNA pyrosequencing. Genome Bio/ 2007, 8:R143.

50. Biémont C, Vieira C: Junk DNA as an evolutionary force. Nature 2006, 443:521-524.

51. Castoe TA, Hall KT, Guibotsy Mboulas ML, Gu W, de Koning AP, Fox SE, Poole AW, Vemulapalli V, Daza JM, Mockler T, Smith EN, Feschotte C, Pollock DD: Discovery of highly divergent repeat landscapes in snake genomes using high-throughput sequencing. Genome Biol Evol 2011, 3:641-653.

52. Junqueira-de-Azevedo ILM, Ho PL: A survey of gene expression and diversity in the venom glands of the pit viper snake Bothrops insularis through the generation of expressed sequence tags (ESTs). Gene 2002, 299:279-291.

53. Junqueira-de-Azevedo ILM, Ching ATC, Carvalho E, Faria F, Nishiyama MY Jr, Ho PL, Diniz MRV: Lachesis muta (Viperidae) cDNAs reveal diverging pit viper molecules and scaffolds typical of cobra (Elapidae) venoms: implications for snake toxin repertoire evolution. Genetics 2006, 172:877-889.

54. Ching AT, Rocha MM, Leme AFP, Pimenta DC, Furtado MFD, Serrano SM, Ho $\mathrm{PL}$, de Azevedo IL J: Some aspects of the venom proteome of the Colubridae snake Philodryas olfersii revealed from a Duvernoy's (venom) gland transcriptome. FEBS Lett 2006, 580:4417-4422.

55. Kordis D, Gubenšek F: Bov-B long interspersed repeated DNA (LINE) sequences are present in Vipera ammodytes phospholipase A2 genes and in genomes of Viperidae snakes. Eur J Biochem 1997, 246:772-779.

56. Kordis D, Gubenšek F: The Bov-B lines found in Vipera ammodytes toxic PLA2 genes are widespread in snake genomes. Toxicon 1998, 36:1585-1590

57. Ikeda N, Chijiwa T, Matsubara K, Oda-Ueda N, Hattori S, Matsuda Y, Ohno M: Unique structural characteristics and evolution of a cluster of venom phospholipase $A_{2}$ isozyme genes of Protobothrops flavoviridis snake. Gene 2010, 461:15-25.

58. Nobuhisa I, Ogawa T, Deshimaru M, Chijiwa T, Nakashima K-I, Chuman Y, Shimohigashi Y, Fukumaki Y, Hattori S, Ohno M: Retrotransposable CR1-like elements in Crotalinae snake genomes. Toxicon 1998, 36:915-920.

59. Sanz L, Harrison RA, Calvete JJ: First draft of the genomic organization of a PIII-SVMP gene. Toxicon 2012, 60:455-469.

60. van de Lagemaat LN, Landry JR, Mager DL, Medstrand P: Transposable elements in mammals promote regulatory variation and diversification of genes with specialized functions. Trends Genet 2003, 19:530-536.

61. Medstrand P, Van de Lagemaat LN, Dunn CA, Landry JR, Svenback D, Mager $\mathrm{DL}$ : Impact of transposable elements on the evolution of mammalian gene regulation. Cytogenet Genome Res 2005, 110:342-345. 
62. Piskurek O, Austin CC, Okada N: Sauria SINEs: novel short interspersed transposable elements that are widespread in reptile genomes. J Mol Evol 2006, 62:630-644.

63. Piskurek O, Okada N: Poxviruses as possible vectors for horizontal transfer of retroposons from reptiles to mammals. Proc Natl Acad Sci USA 2007 104:12046-12051.

64. Oshima K, Okada N: SINEs and LINEs: symbionts of eukaryotic genomes with a common tail. Cytogenet Genome Res 2005, 110:475-490.

65. Luan DD, Korman MH, Jakubczak JL, Eickbush TH: Reverse transcription of R2Bm RNA is primed by a nick at the chromosomal target site: a mechanism for non-LTR retrotransposition. Cell 1993, 72:595-605.

66. Deininger PL, Batzer MA: Mammalian retroelements. Genome Res 2002, $12: 1455-1465$

67. Piskurek O, Nishihara $\mathrm{H}$, Okada N: The evolution of two partner LINE/SINE families and a full-length chromodomain-containing Ty3/Gypsy LTR element in the first reptilian genome of Anolis carolinensis. Gene 2009, 441:111-118

68. International Chicken Genome Sequencing Consortium: Sequence and comparative analysis of the chicken genome provide unique perspectives on vertebrate evolution. Nature 2004, 432:695-716.

69. Alföldi J, Di Palma F, Grabherr M, Williams C, Kong L, Mauceli E, Russell P, Lowe CB, Glor RE, Jaffe JD, Ray DA, Boissinot S, Shedlock AM, Botka C, Castoe TA, Colbourne JK, Fujita MK, Moreno RG, ten Hallers BF, Haussler D, Heger A, Heiman D, Janes DE, Johnson J, de Jong PJ, Koriabine MY, Lara M, Novick PA, Organ CL, Peach SE, et al: The genome of the green anole lizard and a comparative analysis with birds and mammals. Nature 2011, 477:587-591.

70. Kazazian HHJ: Mobile elements: drivers of genome evolution. Science 2004, 303:1626-1632.

71. Cline M, Smooth M, Cerami E, Kushinski A, Landys N, Workman C, Christmas R, Avila-Campilo I, Creech M, Gross B, Hanspers K, Isserlin R, Kelley R, Killcoyne S, Lotia S, Maere S, Morris J, Ono K, Pavlovic V, Pico AR, Vailaya A, Wang PL, Adler A, Conklin BR, Hood L, Kuiper M, Sander C, Schmulevich I, Schwikowski B, Warner GJ, Ideker T, Bader GD: Integration of biological networks and gene expression data using Cytoscape. Nat Protoc 2007, 2:2366-2382.

72. Sharp PA: The centrality of RNA. Cell 2009, 136:577-580.

73. Licatalosi DD, Darnell RB: RNA processing and its regulation: global insights into biological networks. Nat Rev Genet 2010, 11:75-87.

74. Ambros V: The functions of animal microRNAs. Nature 2004, 431:350-355.

75. He L, Hannon GJ: MicroRNAs: small RNAs with a big role in gene regulation. Nat Rev Genet 2004, 5:522-531.

76. Bartel DP: MicroRNAs: target recognition and regulatory functions Cell 2009, 136:215-233.

77. Höck H, Meister G: The Argonaute protein family. Genome Biol 2008, 9:210.

78. Wheeler BM, Heimberg AM, Moy VN, Sperling EA, Holstein TW, Heber S, Peterson KJ: The deep evolution of metazoan microRNAs. Evol Dev 2009, $11: 145-150$

79. Kozomara A, Griffiths-Jones S: miRBase: integrating microRNA annotation and deep-sequencing data. Nucleic Acid Res 2011, 39:D152-D157.

80. Enright AJ, John B, Gaul U, Tuschl T, Sander C, Marks DS: MicroRNA targets in Drosophila. Genome Biol 2003, 5:R1.

81. John B, Enright AJ, Aravin A, Tuschl T, Sander C, Marks DS: Human MicroRNA targets. PLoS Biol 2004, 2:e363.

82. Wuchty S, Fontana W, Hofacker IL, Schuster P: Complete suboptimal folding of RNA and the stability of secondary structures. Biopolymers 1999, 49:145-165.

83. Guerra-Assunção JA, Enright AJ: MapMi: automated mapping of microRNA loci. BMC Bioinformatics 2012, 11:133.

84. Chen K, Rajewsky N: Deep conservation of microRNA-target relationships and 3' UTR motifs in vertebrates, flies, and nematodes. Cold Spring Harb Symp Quant Biol 2006, 71:149-156.

85. Lewis BP, Burge CB, Bartel DP: Conserved seed pairing, often flanked by adenosines, indicates that thousands of human genes are microRNA targets. Cell 2005, 120:15-20.

86. Grimson A, Farh KK, Johnston WK, Garrett-Engele P, Lim LP, Bartel DP: MicroRNA targeting specificity in mammals: determinants beyond seed pairing. Mol Cell 2007, 27:91-105.

87. Ma JB, Yuan YR, Meister G, Pei Y, Tuschi T, Patel J: Structural basis for 5 '-end-specific recognition of guide RNA by the $A$. fulgidus Piwi protein. Nature 2005, 434:666-670.
88. Parker JS, Roe SM, Barford D: Structural insight into mRNA recognition from Piwi domain-siRNA guide complex. Nature 2005, 434:663-666.

89. Bon C, Changeux JP, Jeng TW, Fraenkel-Conrat H: Postsynaptic effects of crotoxin and its isolated subunits. Eur J Biochem 1979, 99:471-481.

90. Faure G, Copic A, Le Porrier S, Gubensek F, Bon C, Krizaj I: Crotoxin acceptor protein isolated from Torpedo electric organ: binding properties to crotoxin by surface plasmon resonance. Toxicon 2003, 41:509-517.

91. Pereañez JA, Gómez ID, Patiño AC: Relationship between the structure and the enzymatic activity of crotoxin complex and its phospholipase $A_{2}$ subunit: An in silico approach. J Mol Graph Model 2012, 35:36-42.

92. Baek D, Villen J, Shin C, Camargo FD, Gygi SP, Bartel DP: The impact of microRNAs on protein output. Nature 2008, 455:64-71.

93. Vidal N, Hedges SB: The phylogeny of squamate reptiles (lizards, snakes, and amphisbaenians) inferred from nine nuclear protein-coding genes. Comptes Rendus Biologies 2005, 328:1000-1008.

94. Paine MJ, Desmond HP, Theakston RDG, Crampton JM: Gene expression in Echis carinatus (carpet viper) venom glands following milking. Toxicon 1992, 30:379-386.

95. Margulies M, Egholm M, Altman WE, Attiya S, Bader JS, Bemben LA, Berka J, Braverman MS, Chen Y, Chen Z, Dewell SB, Du L, Fierro JM, Gomes XV, Godwin BC, He W, Helgesen S, Ho CH, Ho CH, Irzyk GP, Jando SC, Alenquer MLI, Jarvie TP, Jirage KB, Kim J, Knight JR, Lanza JR, Leamon JH, Lefkowitz $S M$, Lei $M$, et al: Genome sequencing in microfabricated high-density picolitre reactors. Nature 2005, 437:376-380

96. Schmieder R, Edwards R: Quality control and preprocessing of metagenomic datasets. Bioinformatics 2011, 27:863-864.

97. Smit AFA, Hubley R, Green P: RepeatMasker Open-3.0.. http://repeatmasker. org.

98. Altschul SF, Gish W, Miller W, Myers EW, Lipman DJ: Basic local alignment search tool. J Mol Biol 1990, 215:403-410.

99. Papadopoulos JS, Agarwala R: COBALT: constraint-based alignment tool for multiple protein sequences. Bioinformatics 2007, 23:1073-1079.

100. Mortazavi A, Williams BA, McCue K, Schaeffer L, Wold B: Mapping and quantifying mammalian transcriptomes by RNA-Seq. Nat Methods 2008, 5:621-628.

101. Tarazona S, García-Alcalde F, Dopazo J, Ferrer A, Conesa A: Differential expression in RNA-seq: a matter of depth. Genome Res 2011, 21:2213-2223.

102. Li W, Godzik A: Cd-hit: a fast program for clustering and comparing large sets of protein or nucleotide sequences. Bioinformatics 2006 22:1658-1659.

103. Niu BF, Fu LM, Sun SL, Li WZ: Artificial and natural duplicates in pyrosequencing reads of metagenomic data. BMC Bioinformatics 2010, 11:187.

104. Stefani G, Slack FJ: A 'pivotal' new rule for microRNA-mRNA interactions. Nature Struct \& Mol Biol 2012, 19:265-266.

105. Chi SW, Hannon GJ, Darnell RB: An alternative mode of microRNA target recognition. Nature Struct \& Mol Biol 2012, 19:321-328.

106. Seelbach M, Schwanhausser B, Thierfelder N, Fang Z, Khanin R, Rajewsky N: Widespread changes in protein synthesis induced by microRNAs. Nature 2008, 455:58-63.

doi:10.1186/1471-2164-14-234

Cite this article as: Durban et al:: Integrated "omics" profiling indicates that miRNAs are modulators of the ontogenetic venom composition shift in the Central American rattlesnake, Crotalus simus simus. BMC Genomics 2013 14:234. 